OPEN ACCESS

Edited by:

Ubaldo Armato

University of Verona, Italy

Reviewed by:

Lynn Jena,

Queen's University Belfast,

United Kingdom

Peng $\mathrm{Hu}$,

University of Verona, Italy

*Correspondence:

Eoghan J. Mulholland eoghan.mulholland@well.ox.ac.uk

Specialty section:

This article was submitted to Biomaterials,

a section of the journal

Frontiers in Bioengineering and Biotechnology

Received: 27 August 2019 Accepted: 24 April 2020

Published: 04 June 2020

Citation:

Mulholland EJ (2020) Electrospun Biomaterials in the Treatment and

Prevention of Scars in Skin Wound Healing.

Front. Bioeng. Biotechnol. 8:481.

doi: 10.3389/fbioe.2020.00481

\section{Electrospun Biomaterials in the Treatment and Prevention of Scars in Skin Wound Healing}

\author{
Eoghan J. Mulholland *
}

Gastrointestinal Stem Cell Biology Laboratory, Wellcome Trust Centre for Human Genetics, University of Oxford, Oxford, United Kingdom

Electrospinning is a promising method for the rapid and cost-effective production of nanofibers from a wide variety of polymers given the high surface area morphology of these nanofibers, they make excellent wound dressings, and so have significant potential in the prevention and treatment of scars. Wound healing and the resulting scar formation are exceptionally well-characterized on a molecular and cellular level. Despite this, novel effective anti-scarring treatments which exploit this knowledge are still clinically absent. As the process of electrospinning can produce fibers from a variety of polymers, the treatment avenues for scars are vast, with therapeutic potential in choice of polymers, drug incorporation, and cell-seeded scaffolds. It is essential to show the new advances in this field; thus, this review will investigate the molecular processes of wound healing and scar tissue formation, the process of electrospinning, and examine how electrospun biomaterials can be utilized and adapted to wound repair in the hope of reducing scar tissue formation and conferring an enhanced tensile strength of the skin. Future directions of the research will explore potential novel electrospun treatments, such as gene therapies, as targets for enhanced tissue repair applications. With this class of biomaterial gaining such momentum and having such promise, it is necessary to refine our understanding of its process to be able to combine this technology with cutting-edge therapies to relieve the burden scars place on world healthcare systems.

Keywords: nanofibers, nanotechnology, electrospinning, polymer, drug delivery, tissue engineering, wound healing, scars

\section{INTRODUCTION}

Pathological scar formation is the physiological conclusion of wound healing, and so it is important to understand its underlying cellular and molecular processes in order to apprehend how a scar is formed, but also for the exploration of potential therapeutic targets. Currently, scarring is a huge burden on world healthcare, and the global scar treatment market is projected to represent as much as $\$ 34.9$ billion by the year $2023^{1}$. Indeed, scarring can lead to many adverse side effects such as reduced mobility, compromised function in organs such as the liver or kidney, and the development of functional disabilities such as the psychological stress (Krafts, 2010; Sarrazy et al., 2011). A plethora of treatment options are available for scarring including topical treatments and

\footnotetext{
${ }^{1}$ https://www.prnewswire.com/news-releases/global-scar-treatment-market-2013-2018--2023---rise-in-online-retailingof-scar-treatment-products-300698219.html
} 


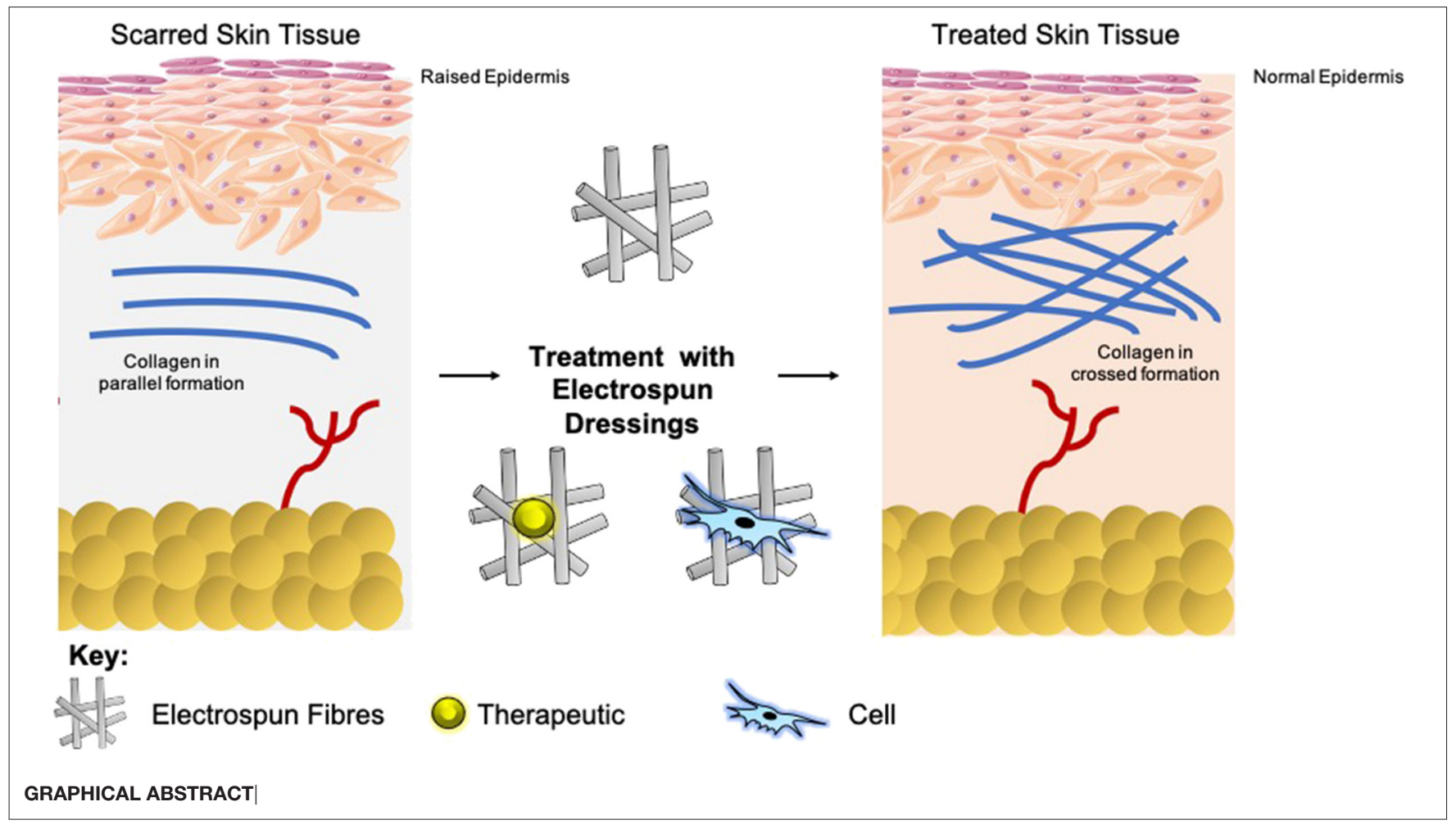

dressings but are met with many limitations and are proving ineffective. This review will explore the use of electrospun nanofibers as novel instruments for efficient wound healing and reducing scar formation. The large surface area to volume ratio make electrospun fibers attractive options as they offer therapeutic incorporation capabilities whilst also being absorptive. A key focus of this review will be how these nanofibers can be applied alone, but also in conjunction with pharmacotherapies and cells for effective skin repair.

\section{WOUND HEALING}

Wound healing is a highly complex process which stems from three well-defined phases: inflammation, proliferation, and remodeling. Inflammation is the immediate response phase, commencing with the contact of platelets from blood with exposed collagen at the site of injury (Qin, 2016). This contact initiates the formation of a fibrin clot, comprised of the platelets, thrombin, and fibronectin. The fibrin clot acts as a reservoir of cytokines and growth factors, stimulating inflammatory mediators to migrate to the wound, while also providing an architecture for infiltrating cells (Hsieh et al., 2017). For example, transforming growth factors (TGF- $\alpha$, TGF- $\beta$ ) is a highly significant signaling pathway initiated by platelets within the fibrin clot (Ramirez et al., 2014). TGFs draw leukocytes to the injury site and initiate the inflammatory stage (Kryczka and Boncela, 2015). These leukocytes support the secretion of additional cytokines, e.g., platelet-derived growth factor (PDGF), interleukin-1 (IL-1), and fibroblast growth factor (FGF) (Grove and Kligman, 1983). During proliferation, the secondary stage of wound healing, TGF signaling becomes increasingly crucial, especially in cell types such as keratinocytes, macrophages, and fibroblasts, essential for the transcription of collagen, fibronectin, and proteoglycan. Additionally, TGFs prevent the release of protease enzymes responsible for the degradation of the matrix and activates inhibitors of protease production (Broughton et al., 2006). As proliferation progresses, fibroblasts are the principal cell type. Fibroblasts are of mesenchymal origin and are accountable for new matrix production, resulting in the restoration of tissue homoeostasis (Darby et al., 2014). Remodeling, the final stage, can last up to 1 -year after injury. Collagenase enzymes secreted from fibroblasts, macrophages, and neutrophils, cleave the molecules of collagen, thereby breaking it down (Caley et al., 2015). This results in Type I collagen gradually replacing Type III collagen, which in time increases the tensile strength of the new tissue (Longaker et al., 2008). The collagen fibers in the wound tissue are thinner than that of normal dermal collagen. These thinner fibers will gradually thicken over time and organize along the stress lines of the injury. This resulting scar tissue, however, will never be as strong as the preceding normal tissue (White et al., 1971; Schilling, 1976; Corr et al., 2009). Many studies suggest that variations in inflammation during the wound healing process are directly related to the extent of scar tissue formation (Lim et al., 2006). For example, fetal wound healing presents with a lack of typical inflammatory markers and is "scarless" up to a certain age (Longaker et al., 2008). In adult wound healing, polymorphonuclear leukocytes are recruited to the site of injury, followed by macrophages and lymphocytes. Contrastingly, fetal wounds are void of polymorphonuclear leukocytes, and as 
healing progresses, fetal macrophages enter the wound site but in lesser numbers than that of an adult (Mackool et al., 1998). This characteristic lack of an inflammatory response may be credited to a dearth in appropriate signaling in fetal wounds, and the fundamentally immature condition of fetal inflammatory cell populations. Many non-healing wounds fail to switch from the inflammatory phase into the proliferative phase, thus resulting in abnormal wound repair.

\section{SCAR FORMATION}

Scars present as a significant burden to healthcare systems, and so are a catalyst for global research for prevention and reduction (Mirastschijski et al., 2015; Barnes et al., 2018). A mature scar consists predominantly of Type I collagen (Marshall et al., 2018). Within scar tissue, this collagen is arranged in bundles parallel to the skins surface, as opposed to a non-parallel conformation in normal skin. This parallel configuration in scar tissue equates to an overall reduction in tensile strength (van Zuijlen et al., 2003). The epidermal basement membrane presents with a more flattened nature as opposed to normal skin, as it does not contain the rete pegs which typically infiltrate the dermis (Monaco and Lawrence, 2003). Furthermore, scar tissue is void of other classic dermal adjuncts such as hair follicles or sweat glands (Fu et al., 2005; Kiani et al., 2018). Upon maturation, the concentration of fibroblasts with the scar tissue depletes, which in combination with the lack of dermal adjuncts results in a dermal layer comprising of few cells. The extracellular matrix (ECM) of this tissue has less elastin than healthy tissue, which contributes to the loss in tensile strength, and means that re-injury is more probable (Kordestani, 2019).

The extent of fibrosis post-injury varies between organs and tissues. When the molecular regulation of the remodeling phase of wound healing is inefficient or disturbed, more problematic scars occur: hypertrophic scars and keloids. Hypertrophic scars typically develop post-surgery or from other trauma such as burns (Carswell and Borger, 2019). Keloids contrast from hypertrophic scars in that they grow beyond the natural margins of the initial damaged tissue (Berman et al., 2017). These keloidal scars do not naturally revert, as opposed to hypertrophic scares which typically regress to a degree within 6 months. Histologically speaking, keloid, and hypertrophic scars are distinguishable by a difference in collagen fiber architecture, presence of myofibroblasts which are alpha-smooth muscle actinpositive, and the degree of angiogenesis (Carswell and Borger, 2019). Keloids are characterized by thick fibers of collagen, while hypertrophic scars encompass thin fibers organized in nodules. The dysregulation to normal collagen maturation is a central influencer on excessive scar formation. Hypertrophic scars contain high concentrations of microvessels, attributed to excess proliferation and loss of functionality of endothelial cells. This phenomenon can be traced back to myofibroblast hyperactivity and the resulting excess collagen fabrication. Myofibroblasts are the principal cell type responsible for scar contraction (Li and Wang, 2011), and are derived from fibroblasts $\sim 2$ weeks postwounding (Singer and Clark, 1999). PDGF and TGF- $\beta$ stimulate this cellular differentiation and the resultant contractile force exerted by the myofibroblasts enables wound edges in humans to come together, at a rate of $\sim 0.75 \mathrm{~mm}$ a day (Figure 1) (Werner and Grose, 2003; Storch and Rice, 2005). Of course, in normal scars this wound contraction is an essential process; however, myofibroblasts typically go through apoptosis postepithelialization, thus halting contractive pathways (Desmoulière et al., 2005). In hypertrophic scars, these myofibroblasts do not apoptose beyond epithelialization and so cause persistent contraction, resulting in functional implications to the skin (Ehrlich et al., 1994). Keloid scars, however, are smooth muscle actin negative (Ehrlich et al., 1994). This can be attributed to the presence of protomyofibroblasts in keloids, which can manufacture large quantities of ECM but not the force to contract lesions. This explains why functional defects resulting from contraction are only observed in hypertrophic scarring. Typically, the granulation tissue continues to expand and secrete growth factors, while lacking molecules essential for apoptosis or ECM remodeling such as cleaved-caspase 3,-8, and-9 (Yang et al., 2016). Indeed, upregulation of p53 expression has been reported in scarring phenotypes, a protein important for the inhibition of apoptosis (Tanaka et al., 2004).

Most lab-based in vivo assessment of wound closure and development is performed in rodents. This is mainly due to the high-throughput and low costs of these systems. However, it is important to understand that rodent wounds close differently to that of human's, primarily due to the process of contraction. This is mainly owed to an extensive subcutaneous striated muscle layer known as the panniculus carnosus that is virtually non-existent in humans. In rodents however, the panniculus carnosus allows the skin to move independently of the deeper muscles and is accountable for the rapid contraction of skin following injury. This physiological difference therefore creates difficulties to replicate the wound closure processes of human skin. This is a universal problem, one that is noted in much recent literature (Wang et al., 2013; Hu et al., 2018). Wang et al. discussed this problem, proposing an alternative model which involved splinting rodent wounds to inhibit contraction and force re-epithelization. Nevertheless, this model also encountered limitations including inflammation induced from sutures used to anchor the splint to the mouse skin which could influence any molecular changes (Dunn et al., 2013). Formerly published reports utilizing the splinted wound model lack descriptive details of splint management and exclusion criteria for removing animals from analysis in cases where splints might have been incompletely secured due to suture rupture or damage to the splint by the animal.

Another alternative method is the direct suturing of a scaffold to the edges of the experimental wounds. Anjum et al. conducted wounding experiments of this nature with $(\mathrm{Nu} / \mathrm{Nu})$ mice and found that contraction is still observed in all wounds, however a more reepithelialization route was observed in the central wound regions (Anjum et al., 2017). However, limitations of this method again point to the provoking of an inflammatory response and coincidently with an increased risk of surgical site infections (He et al., 


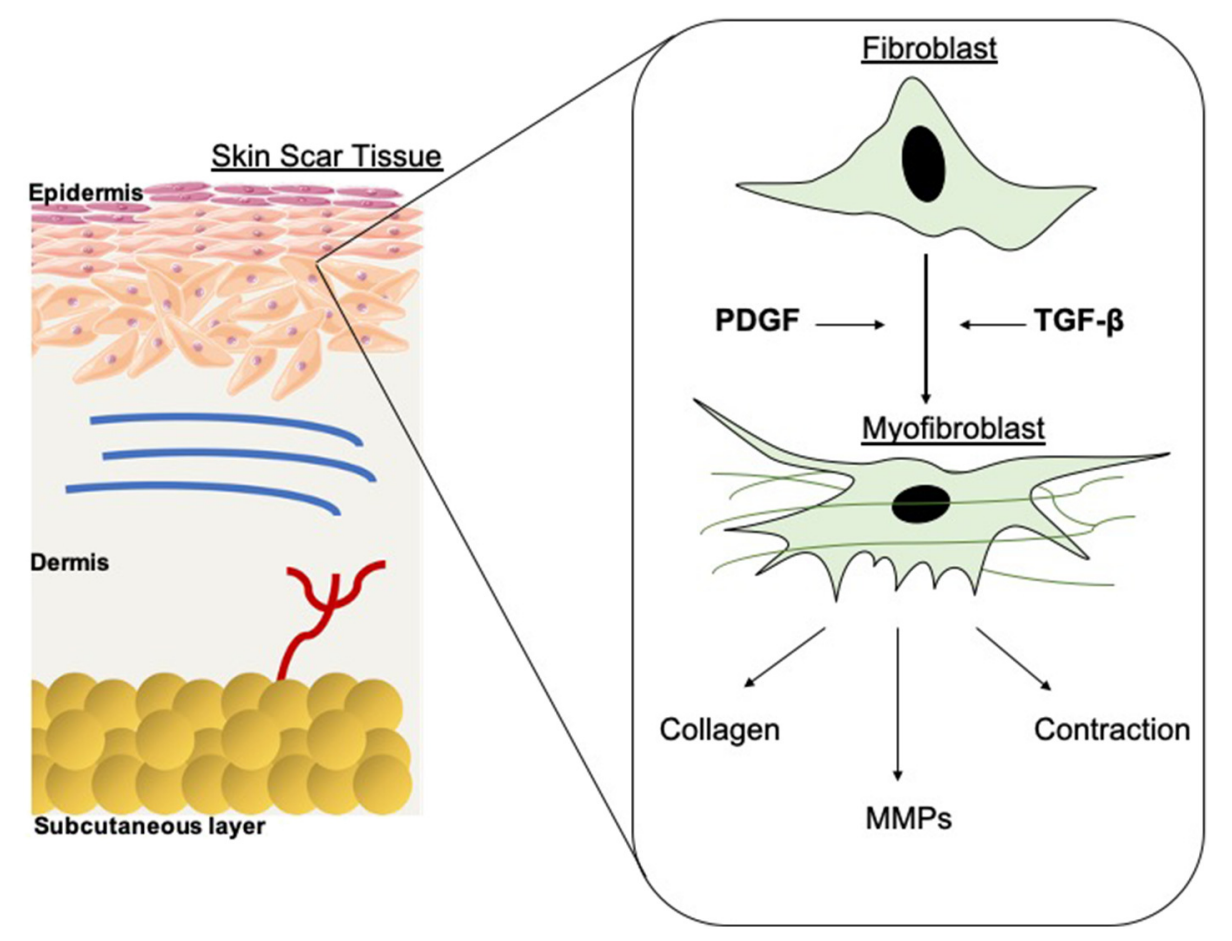

FIGURE 1 | Schematic of fibroblast differentiation into myofibroblasts within scar tissue. TGF- $\beta$ and PDGF stimulate the differentiation of myofibroblasts from fibroblasts, thus contributing to wound contraction. The contractile force is delivered by the myofibroblasts until re-epithelialisation is complete then they go through apoptosis. MMPs are also released and are essential in the remodeling phase of wound healing and scar formation. However, in hypertrophic scarring this myofibroblast depletion is not well-orchestrated, resulting in functional defects.

2009). Suture knots, for example, can act as platforms for bacterial colonization and reproduction (Mashhadi and Loh, 2011).

To overcome these limitations, porcine models of wound healing are often used. Pigs are anatomically and physiologically similar to humans, and therefore can be considered excellent models of human diseases (Seaton et al., 2015; Acevedo et al., 2019). Indeed, the skin of pigs and humans are similar in that they have a relatively thick epidermis and dermal papillae (Montagna and Yun, 1964).

\section{CURRENT SCAR TREATMENTS}

There is a vast array of current treatments for scars which come in a variety of forms. Topical treatments such as Mederma ${ }^{\circledR}$ Skin Care gel (Merz Pharmaceuticals, Greensboro, NC, USA) ${ }^{2}$ is available over the counter. The active ingredients of Mederma ${ }^{\circledR}$ gel include onion extract; however, this product displayed no benefit when tested in a trial involving patients subjected to Mohs microsurgery (Jackson and Shelton, 1999).

Surgical revision is sometimes utilized for hypertrophic or normal scars. It is common practice in the clinic to wait several months before surgically excising scars, allowing them to become fully mature (Thomas and Somenek, 2012). The most direct excision technique for scar removal is surgical removal followed by linear closure of the skin. Surgery as a treatment, however, can result in excessive tension across the wound area or infection (Marshall et al., 2018). There are also many injectable treatments which can be used for scar treatment, including corticosteroids which is common therapy for keloid and hypertrophic scars (Thomas and Somenek, 2012).

A further example is Botulinum toxin [BOTOX ${ }^{\circledR}$ Cosmetic (onabotulinumtoxin $\mathrm{A})^{3}$, Allergan, Irvine, $\left.\mathrm{CA}\right]$, which is linked with improving scar appearance (Gassner et al., 2000). However, in a clinical trial in humans who presented with forehead wounds in an emergency department and were treated with botox or placebo, there was no difference in scar appearance in 3 of 4 visual scales upon suturing (Ziade et al., 2013).

Dressings are the traditional treatment mode for wound healing and scar reduction as a means of protecting the wounds, keeping a moist microenvironment, and offloading tension from the skin (Commander et al., 2016). Indeed, the use of simple paper tape alone has shown promise. When paper tape was applied to patients with cesarean section wounds for 12 weeks post-surgery, there was a reduction in scar formation, and it decreased the probability of the patient developing hypertrophic scars (Atkinson et al., 2005).

${ }^{2} \mathrm{https} / / /$ www.mederma.com/

$\overline{{ }^{3} \text { https://hcp.botoxcosmetic.com/Contact }}$ 


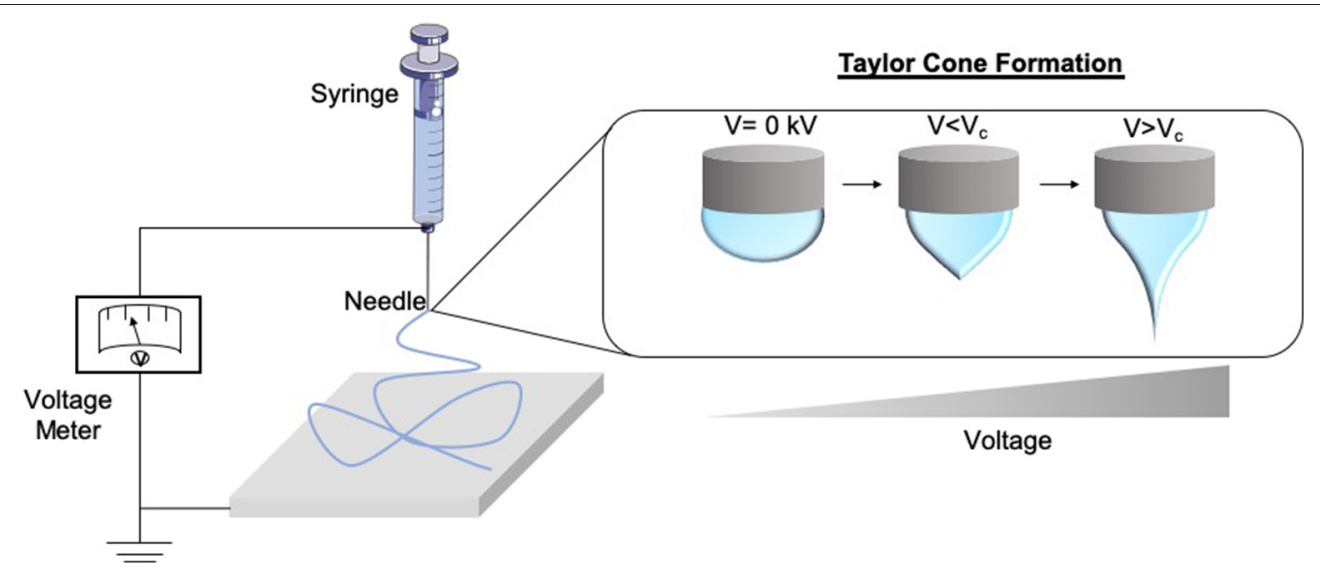

FIGURE 2 | Schematic of the formation of the Taylor Cone. As the voltage supply to the electrospinning rig increases and surpasses the critical voltage $\left(V_{c}\right)$, the repulsion within the charged polymer overcomes its surface tension, fabricating solid nanofibers onto the collector. This is known as the Taylor Cone effect.

With current treatments offering varying degrees of efficacy it is imperative to develop novel modalities of treatment. The electrospinning of polymers holds potential in this regard.

\section{ELECTROSPINNING}

Electrospinning forms fibres through the application of an electrostatic field to a polymer solution (Cui et al., 2007; Bhardwaj and Kundu, 2010; Lagaron et al., 2017). The process of electrospinning can produce fibers right down to nanoscale and have applications in various fields, for example, wound dressings, drug delivery, and tissue engineering devices. The process itself is rapid and can be scaled to meet industrial demands to continuously produce fibers. This technique involves the use of a high voltage field strength from as low as $1 \mathrm{kV} \mathrm{cm}$, to charge the surface of a polymer solution droplet, subsequently inducing the ejection of a liquid jet toward a grounded surface. When the voltage reaches the optimal threshold [critical voltage $\left(V_{C}\right)$ ] by radial charge repulsion, the single jet will divide into multiple filaments; this is recognized as the Taylor cone effect (Figure 2). This cone formation results in the construction of solidified fibers as the solvent evaporates. The $\mathrm{V}_{\mathrm{C}}$ value varies between polymers due to alterations in chemical properties (Quinn et al., 2018). Solution properties such as viscosity, concentration, and dielectric constant, and operational parameters including the strength of the applied voltage, jet to collector distance, and flux, will all affect the morphology of the resulting fibers (Sencadas et al., 2012; Haider et al., 2015). Electrospun fibers possess high surface area to volume ratios, meaning they exhibit many of the desirable properties of an effective wound dressing such as protection from mechanical stimuli and providence of excellent gaseous exchange, and as such a lot of research has gone into optimizing them for this application. The following sections, therefore, explore the use of electrospun fibers in the treatment of scars and the potential future applications this technology could hold as a therapeutic (Table $\mathbf{1}$ ).

Electrospinning is a versatile process which encompasses many different modes of fabrication for the incorporation of therapeutics (Figure 3). Blending is the predominant method for drug incorporation into electrospun nanofibers. The process of blending consists of drug or drug precursors encapsulated by means of dissolving or dispersing it into the polymer solution, before subsequent electrospinning. As the drug itself is in direct contact with the polymer, the drug-polymer interaction must be analyzed to ensure functionality is retained and that the drug can be adequately released from the product fibers. For example, Yang et al. investigated the use of gold nanoparticles modified with an antibacterial intermediate (6-aminopenicillanic acid) for wound healing applications. The gold nanoparticles were assimilated into electrospun nanofibers composed of polycaprolactone (PCL) and gelatin by blending. The nanoparticles release profile was investigated by nanofiber dipping into saline. The results showed that after Day $120.4 \%$ of the gold had been released, increasing to $65.7 \%$ by Day 7. Burst release was apparent within the initial days which can be attributed to a percentage of the gold existing near the surface of the fibers (Yang et al., 2017).

Modification of nanofiber surfaces to allow incorporation of therapeutics is another method for drug and cell loading (Prabhakaran et al., 2008; Ma et al., 2011; Wakuda et al., 2018). This method is advantageous for avoiding burst discharge of therapeutics and results in a more gradual release profile (Im et al., 2010). This technique is particularly beneficial for biomolecular therapeutics such as enzymes as surface conjugation, and slow-release helps to preserve functionality (Zamani et al., 2013). Plasma treatment of polymers is a typical method of surface modification. Nanofiber treatment with plasma in the presence of oxygen, ammonia, or air has resulted in the generation of amine or carboxyl groups on the surface of the fibers (Baker et al., 2006; Yan et al., 2013). This process functionalizes fibers for a variety of applications, such as the adhesion of the collagen or gelatin, which are key proteins found in the extracellular matrix, and so can improve cell adhesion and proliferation (He et al., 2005; Koh et al., 2008). It has been shown that poly(lactic-co-glycolic acid) PLGA nanofibers can be transformed to contain carboxylic acid groups through plasma glow discharge in the presence of oxygen and gaseous 
TABLE 1 | Therapeutic potential of various electrospun polymers including therapy loaded nanofibers and tissue engineering options.

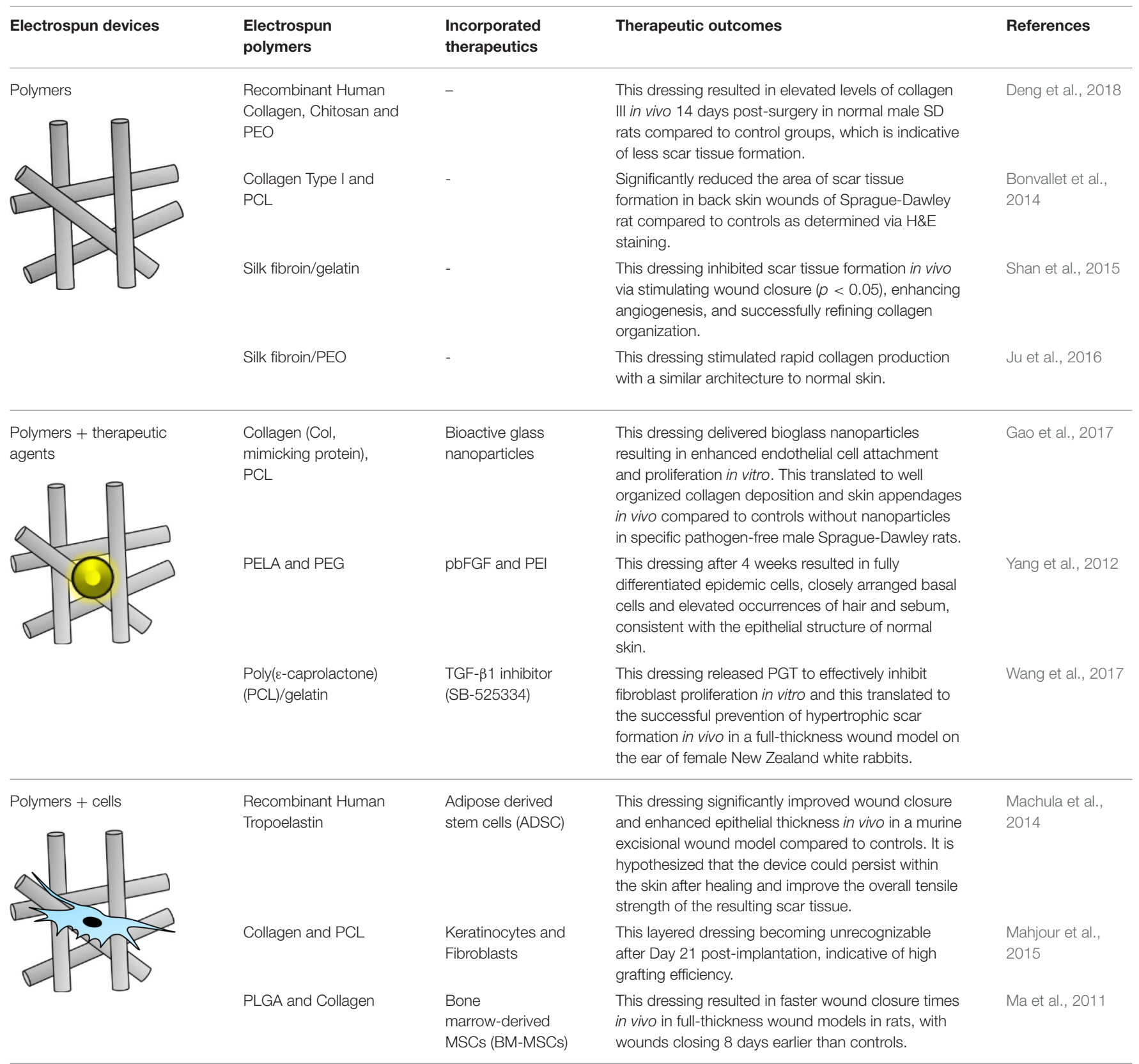

acrylic acid (Park et al., 2007). These fibers exhibited enhanced fibroblast cell adhesion and proliferation, desirable properties for wound healing.

The fabrication of core/shell nanofibers is another attractive method of bioactive incorporation into electrospun nanofibers. The production of electrospun core-shell nanofibers is accomplished through either co-axial or emulsion electrospinning. Co-axial electrospinning is a two-stream process that results in the fabrication of multipolymer fibers with the inner stream being the "core," and the outer polymer passed stream forms the shell (Jiang et al., 2014). This method is auspicious for the incorporation of fragile cargos (e.g., DNA or growth factors) as the therapeutic interaction with the shell polymer blend which may be produced with harsh solvents is minimized, therefore preserving the cargo (Ghosh et al., 2008; Xie et al., 2016; Cheng et al., 2019). Wei et al. utilized this technique for the development of a wound dressing, comprising a PCL core and collagen shell nanofibers. The shell was blended with silver nanoparticles to take advantage of the anti-bacterial activity, and the core permeated with vitamin A, which has been shown to help with wound healing by increasing intra- and extracellular hydration (Campos et al., 1999; Wei et al., 2016). Emulsion electrospinning produces nanofibers of core/shell morphology by first introducing an emulsion into an initial 


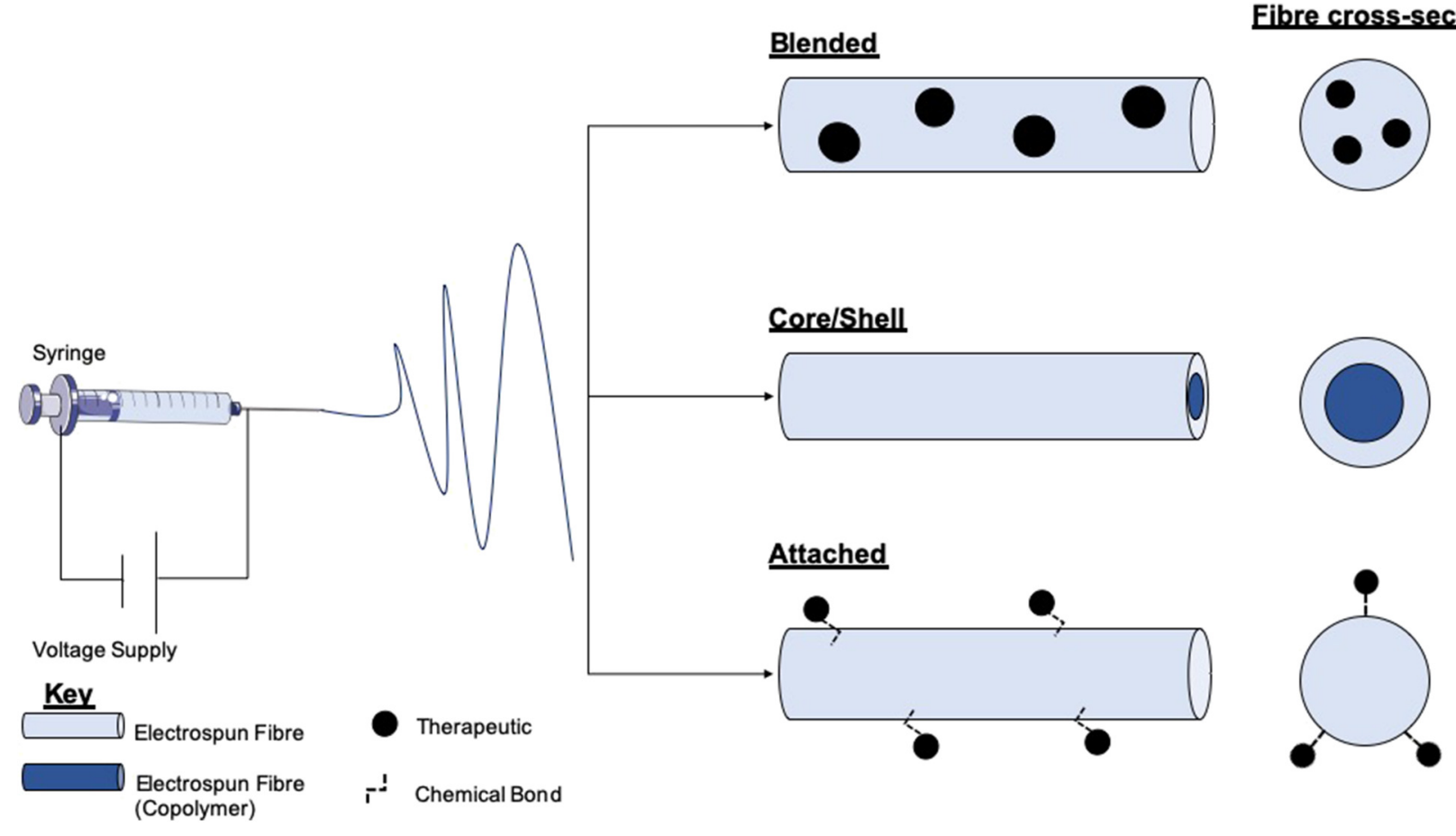

FIGURE 3 | Schematic of electrospinning equipment and the resultant fibers and therapy loaded variants. The electrospinning set-up comprises a high voltage $(\mathrm{V})$ supply which is connected to a syringe loaded with a polymer solution. Within the blending technique therapeutics or therapeutic precursors are mixed with polymer solutions before electrospinning. Either co-axial or emulsion electrospinning produces core/shell morphology fibers. This method allows for the encapsulation of therapeutics in either layer. Therapeutic attachment to fibers post-electrospinning allows for the loading of fragile molecules which cannot endure the electrospinning process.

polymer solution before the addition of a surfactant to isolate the different phases from each other (Liao et al., 2009). Castro et al. manufactured nanofibers composed of PCL and PCL/gelatin, which retained and delivered ketoprofen by solution and emulsion electrospinning, respectively. It was reported that using emulsion electrospinning of PCL/gelatin could diminish the burst release of ketoprofen compared with single PCL nanofibers, and sustained drug release for $>100 \mathrm{~h}$. Furthermore, the combination of gelatin into the nanofibers resulted in an increase in the cell proliferation of L929 fibroblast cells (murine) (Basar et al., 2017). It should be noted however that emulsion electrospinning can cause damage to molecules such as DNA via interface tension between the organic and aqueous phases within the emulsion (He et al., 2012).

\section{ELECTROSPINNING POLYMERS FOR SCAR TREATMENT}

With the process of electrospinning being so versatile, a plethora of both synthetic and natural polymers can be processed to form fibrous structures with the potential to promote scar-free wound healing. Expectedly, not every polymer can be easily electrospun. Many factors influence this ability, including polymer viscosity, concentration, and entanglement. For polymers with inadequate characteristics for electrospinning, a copolymer can be employed to improve mechanical properties. Alginate is an example of a naturally occurring polymer with a well-noted history for improving wound healing due to its excellent ability to swell and maintain a moist microenvironment, which aids healing (Aderibigbe and Buyana, 2018). However, alginate alone does not possess ideal attributes for electrospinning due to its low chain entanglement (Nie et al., 2008). Poly (vinyl alcohol) (PVA) is a reputable polymer for electrospinning and as a result is frequently selected as a copolymer. Indeed, PVA is extensively used on an industrial scale and is favored in the medical industry due to excellent physical properties, processability, and biocompatibility. Tarun et al. developed an electrospun matrix composed of PVA/ sodium alginate (Tarun and Gobi, 2012). It was demonstrated that the matrix displayed excellent water vapor transmission rates, thus maintaining a moist wound microenvironment. Furthermore, in vivo studies using the full-thickness wound model in rats exhibited seemingly new epithelium development, void of any local adverse reactions. Indeed, the movement of epithelial cells across the surface of a wound is enabled in a wound that is kept moist, and in turn, promotes efficient healing (Field and Kerstein, 1994). Wounds that are kept moist typically present with less scar tissue formation (Atiyeh et al., 2003).

A further example of a natural polymer includes chitosan, which has noted antibacterial and antifungal properties, which would be highly beneficial for a wound dressing. It was suggested 
by Ignatova et al. that the crosslinking of PVA/Q-chitosan (a chitosan derivative) through the photo-crosslinking electrospinning procedure, would have antimicrobial effects on both Gram-positive and Gram-negative bacteria (Ignatova et al., 2006). The author's results showed that the matrix had exceptional resistance to the growth of bacteria exhibiting activity against $E$. coli and S. aureus. However, it is important to note that with polymers like chitosan there are drawbacks. Chitosan, as an example, is poorly soluble (Shete et al., 2012), and so tends to be dissolved in acidic conditions, namely using acetic acid or trifluoroacetic acid for example (Geng et al., 2005; Bazmandeh et al., 2019; Gu et al., 2019). The toxicity and cost associated with such solvents can imped the potential of chitosan in wound and anti-scarring therapies (Mengistu Lemma et al., 2016), however, during the electrospinning process much of the solvent evaporates under ideal conditions, and so could help alleviate these unwanted side effects when harsher solvents are required (Golecki et al., 2014; Haider et al., 2015).

Another natural polymer of noted potency as a woundhealing material is silk fibroin, a protein produced by some insects (e.g., silkworm). Fibroin makes for an excellent wound repair candidate as it is highly biocompatible, contains antiinflammatory properties, and has notable anti-scarring potential. As such, much attention has turned to the electrospinning of silk to fabricate bioactive wound dressings. For example, $\mathrm{Ju}$ et al. developed electrospun silk fibroin nanofibers as a dressing material for the treatment of burn wounds. The authors found that the expression of IL- $1 \alpha$, which is proinflammatory, had significantly lower expression levels in silk fibroin treated skin compared to a gauze control treatment in the skin of male Sprague-Dawley rats where second degree burn wounds were induced on the backs. Further to this, the expression profile of TGF- $\beta 1$ peaked at Day 21 postwounding before declining, compared to at in gauze treated wounds which crested at Day 7. It was also noted that the silk fibroin nanofibers induced rapid collagen formation, which organized within the wound in a similar fashion to that of normal skin as opposed to a scarring composition (Ju et al., 2016).

\section{ELECTROSPUN POLYMERS WITH ADDED THERAPEUTICS FOR SCAR TREATMENT}

With the variety of production avenues for electrospinning nanofibers (blending, core/shell, attachment), there lays the opportunity for the incorporation and delivery of a variety of anti-scaring therapeutics. As discussed, alginate offers an excellent polymer choice for wound dressings as it promotes a moist wound environment, and hence reduces the extent of scarring. In a study by Shalumon et al. the use of electrospun sodium alginate/PVA nanofibers loaded with $\mathrm{ZnO}$ nanoparticles (via the blending method) as an antibacterial wound dressing was explored. The study concluded that a concentration of between 0.5 and $5 \%$ is required for the fibers to have antibacterial activity as tested with S. aureus and E. coli, with minimal cytotoxic effects (using L929 murine fibroblast cells) (Shalumon et al.,
2011). These nanofibers were tested in vivo using C57BL/6J mice, where UVB irradiation was employed to produce visible skin lesions, and scar formation was evident within 48-96h. When these lesions where treated with the nanofiber dressings it was reported that no burn marks were detectible after $24 \mathrm{~h}$ post-injury. This rapid recovery was further confirmed by the downregulation of inflammatory cytokines IL-6, IL-1B, and TNFa after $24 \mathrm{~h}$ compared to untreated controls. Taken together this electrospun device shows excellent potential for the reduction of scar tissue formation in a burn wound model (Hajiali et al., 2016).

A historic but still pertinent avenue for the treatment of wounds and scars is the use of essential oils (Sequeira et al., 2019). Previous research as developed electrospun nanofibers composed of alginate/polyethylene glycol (PEO) infused with lavender essential oil, for the treatment of UV-induced skin burns. These fibers showed antibacterial efficacy in vitro against $S$. aureus, and furthermore reduced the production of proinflammatory cytokines both in vitro and in vivo (Hajiali et al., 2016). The authors found that the burns of mice treated with the lavender-infused nanofibers healed faster compared to the untreated group. Karami et al. developed electrospun fibers of PCL and polylactic acid (PLA) which encapsulated thymol from thyme essential oil for the treatment of skin infections, with a focus on E. coli and S. aureus (Karami et al., 2013). Application of these nanofibers in vivo using a full-thickness wound model in Male Wistar rats resulted in an enhancement in granulation tissue formation and re-epithelialization at 14 days post-wounding $(92.3 \%)$ compared to gauze $(68 \%)$ and commercial (Comfeel Plus) (87\%) controls. Histologically, the wounds treated with the commercial dressing exhibited some epidermal tissue at day 14, but this was more extensive in the nanofiber treated wounds (Karami et al., 2013). These results demonstrate the power of essential oils as efficient wound healing therapeutics, which could be employed for the reduction in scar tissue formation.

In another study conducted by Gao et al., endothelial progenitor cells were cultured on composite fibers consisting of PCL/collagen and bioactive glass nanoparticles in vitro (Gao et al., 2017). In vivo wound healing studies using specific pathogen-free male Sprague-Dawley rats revealed evident blood vessel formation, as well as upregulation of angiogenic markers such as hypoxia-inducible factor-1 alpha (HIF-1 $\alpha$ ) and vascular endothelial growth factor (VEGF). Throughout the in vivo study, wound healing potential was superior in wounds treated with nanofibers containing the bioglass nanoparticles. These bioglassloaded nanofibers achieved 60\% wound closure in the first week and $\sim 90 \%$ closure with 2 weeks, compared to nanofibers containing no bioglass beads which achieved only 50 and $80 \%$ closure within week 1 and week 2 , respectively. The total area of scar tissue in wounds treated with the bioactive glass-loaded nanofibers was significantly smaller and with highly organized collagen deposition compared to treatment with unloaded nanofibers (Gao et al., 2017).

Many studies have explored the use of electrospun nanomaterials in the treatment of diabetic foot ulcers (DFU). DFU are categorized as a major complication of diabetes mellitus, 


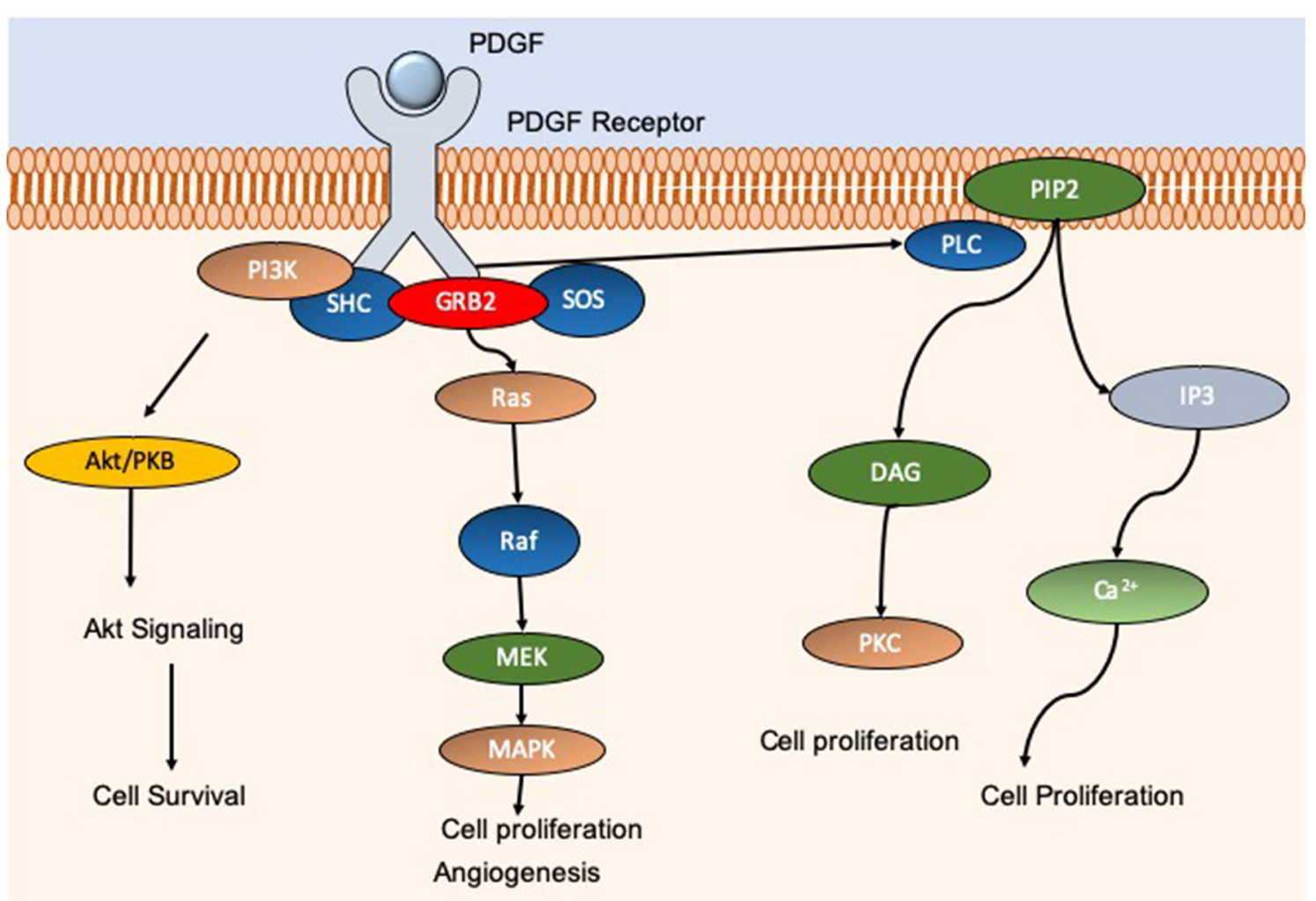

FIGURE 4 | Schematic showing the molecular pathways associated with PDGF. PDGF activation gives rise to an increase in cell proliferation, migration, and angiogenesis through AkT, MAPK, and calcium pathways for example. PDGF is essential for efficient wound repair and minimization of potential scar tissue. Commercial product REGRANEX ${ }^{\circledR}$ utilizes recombinant human PDGF for the treatment of diabetic foot ulcers.

and typically present on the feet, toes, and heels. DFU result from peripheral neuropathy, poor circulation, and impaired immune function, or a combination of these foundations. Of diabetic patients in the USA, $20 \%$ of foot ulcer cases displayed insufficiencies in peripheral atrial supply. Moreover, $50 \%$ of patients primarily displayed peripheral neuropathy, and $\sim 30 \%$ presented with a combination of these conditions (Reiber et al., 1999) ${ }^{4}$ As such, with a wide-reaching cohort of diabetic patients suffering from chronic wounds, there is a continuous need for efficient wound healing options which result in rapid and scar-free results. Indeed, Yang et al. developed an electrospun dressing composed of poly(dl-lactide)-poly(ethylene glycol) (PDLLA-PEG) fibers which had polyethyleneimine (PEI)/pbFGF polyplexes incorporated by the emulsion loading technique, advantageous for the integration of fragile genetic material. PEG was also added to the shell portion of the fibers to aid in smooth release of the cargo. The authors found that the structure was able to sustain release of the polyplexes over a 4-week period, and successful transfection was observed that ensued for over 28 days, enhancing the proliferative capacity of the mouse embryo fibroblast cells in vitro. The efficacy of the fibers in vivo was tested in skin wounds generated on the dorsal area of diabetic male

${ }^{4}$ https://www.niddk.nih.gov/about-niddk/strategic-plans-reports/diabetes-inamerica-2nd-edition
Sprague Dawley (SD) rats. The fibers containing PEI/pbFGF complexes resulted in a significantly higher wound recovery rate compared to untreated wounds, exhibiting improved vascularization and completed re-epithelialization (Yang et al., 2012). These are important outcomes as the more rapid and efficient cell migration corresponds to a reduction in scar tissue formation (Hadjizadeh et al., 2017). Yuan et al. also explored the combination of growth factors and electrospun materials for skin regeneration. The authors utilized a dual-spinneret electrospinner to manufacture fibers composed of chitosan- $\mathrm{PEO}$ and fibrinogen, loading the polymers with PDGF via blending directly before electrospinning (Yuan et al., 2018). PDGF is a critical player in wound repair initiation and progression, acting as a chemotactic instrument for neutrophils, monocytes, and fibroblasts (Sá et al., 2018). Furthermore, PDGF can block fibroblast differentiation into myofibroblasts thus decreasing scar formation (Yuan et al., 2018). Indeed, a therapy option of wound repair termed Regranex ${ }^{\circledR}$ is the only growth factor wound treatment for diabetic ulcers currently FDA approved, utilizing recombinant human PDGF (Figure 4) (Fang and Galiano, 2008). A single daily application of Regranex ${ }^{\circledR}$ has been shown to enhance wound closure, with a $30 \%$ faster healing time observed. It must also be noted that in the case of Regranex ${ }^{\circledR}$ it was previously suggested that it increased the rate of mortality related to malignancy development in patients treated with 
$>3$ tubes of the product, as concluded from a post-marketing retrospective study. However, this warning has since been removed from the product packaging, and many studies have disproved this theory (Ziyadeh et al., 2011; REGRANEX®, 2018). Nevertheless, daily application is considered to be inconvenient for the patient, impacting the quality of life. Thus, the delivery of this growth factor in a controlled manner could be of great benefit. In the instance of Yuan and authors, it was observed that the nanofibers developed exhibited an average fiber diameter of $202.3 \pm 113.2 \mathrm{~nm}$, PDGF integrity was retained, and upon release promoted an increase in the migration rate of human dermal fibroblasts. With regards to cytotoxicity, there was a significant decrease in the viability of cells exposed to the nanofibers (unloaded) at $72 \mathrm{~h}$ post-incubation compared to a no scaffold control. It is postulated that this decrease is the result of the degree of acetylation of chitosan, which has been shown to elicit strong cellular interactions due to positive charges (Aranaz et al., 2009). Indeed, other groups have observed a decrease in cell viability after $24 \mathrm{~h}$ in bladder carcinoma cells exposed to chitosan with a degree of acetylation greater than $50 \%$ (Younes et al., 2016). This is an interesting observation, and so should be factored into the rational for novel wound healing devices. However, it is suggested that this observation may be unique to in vitro experimentation, as prior studies using chitosan observed negligible toxic effect in vivo, linked with metabolic clearance of biodegradation products (Kean and Thanou, 2010; Jeong et al., 2017).

\section{CELL DELIVERY VIA ELECTROSPUN POLYMERS FOR SCAR TREATMENT}

The use of cells in regenerative medicine is widely explored and considered by many to hold great promise ${ }^{5}$. For example, mononuclear umbilical cord cells are easily available and have few associated ethical issues. Furthermore, it has been previously demonstrated that these cell types can be cultured on electrospun nanofibers (Chua et al., 2006).

In light of the advantageous potential of cell therapies for regenerative purposes, they are not without limitations. Therapies of this nature would require a large number of donors, these cells would not survive past low passage numbers, and there is the potential risk of rejection from the host (Venkat et al., 2018). A further example of potential cell therapies includes allogeneic bone marrow cells, which are easily available but carry the risk of rejection and would require specialized techniques for cell harvest and separation. Martinello et al. used allogenic mesenchymal stem cells to treat wounds in a large animal study using female Bergamasca sheep. It was found that at 15 Days post-injury, when compared to a control group, sheep treated with allogeneic bone marrow cells presented with a higher degree of wound closure, reepithelialization, as well as a reduction in inflammation. The latter of which the authors postulate may result in a decreased myofibroblast development and thus scar formation (Martinello et al., 2018).

\footnotetext{
${ }^{5}$ https://www.mayoclinic.org/tests-procedures/bone-marrow-transplant/indepth/stem-cells/art-20048117
}

In saying this, autologous cells helps mitigate the problem of immune rejection, but nevertheless require the same specialized harvesting and separation expertise (Venkat et al., 2018; Ramotowski et al., 2019).

Many studies have explored the use of cells for wound healing and scar tissue minimization. However, the most typical route for this exploration is the direct injection of cells, which can be highly inefficient, and incurs substantial cell death due to shear forces through the injection needle (Burdick et al., 2016). Electrospun nanofibers may be the solution for the efficient and effective delivery of cells for skin regeneration. Electrospun nanofibers have high surface areas, and therefore have the capacity to retain many cultured cells (Chen et al., 2009). For example, it was shown by Zhao et al. that electrospun nanofibers composed of silk fibroin could successfully host cardiomyocytes (Zhao et al., 2019). This capability of electrospun fibers to host cells is thought by many to be owed to the likeness to the natural ECM, fitting to the fibrous nature of collagen, thereby facilitating the natural proliferation of cells (Ramakrishna et al., 2006).

The disadvantage of using these nanofibers for this purpose, however, is the restricted control over pore structure. The pore size in this instance is proportional to the fiber diameters, with smaller diameters resulting in smaller pore sizes, which consequently can decrease cell infiltration (Wu and Hong, 2016). In some cases, cells only infiltrate the uppermost portion of the nanofibers, which reduces the advantages of three-dimensional cell culture. When nanofibers are compared to microfibers in this regard, it has been shown that larger pore sizes, inherent to macrofibers, promote stem cell differentiation, coupled with improved cellular permeation, however nanofibers are associated with higher cell attachment (Wu and Hong, 2016).

Mahjour et al. developed a skin substitute composed of electrospun $\mathrm{PCL} /$ collagen fibers for the treatment of burn wounds. The fibers in question were layered in a composite manner, with different layers infused with keratinocytes (top layer) and fibroblasts (bottom layer). The electrospun fibers were applied in an in vivo mouse model of wound healing. Data collected from the study showed that the cell incorporated composite fibers integrated into the wound bed in a highly effective way, becoming unrecognizable after Day 21 postimplantation. This was in comparison to blank fiber scaffolds which received the lowest score of integration. Furthermore, at Day 21, wounds treated with the cell-incorporated composite fibers had 7\% remaining non-reepithelialized skin and 45\% wound contraction, whereas the blank composite fibers had only $21 \%$ re-epithelialization and 56\% wound contraction (Mahjour et al., 2015).

Mesenchymal stem cells (MSCs) are multipotent stem cells typically isolated from bone marrow, adipose tissues, and the dermis (Orbay et al., 2012). MSCs have shown avid potential in skin repair, promoting angiogenesis, reducing inflammation, and facilitating the establishment of an ECM (Jackson et al., 2012). When MSCs enter an inflammatory environment a switch to an immunomodulatory phenotype is initiated by Interferon-gamma $(\mathrm{IFN} \gamma)$, Tumor Necrosis Factor-alpha (TNF $\alpha$ ) and IL-1 $\beta$ (Ren et al., 2008). When this phenotype is active; there is evidence suggesting that MSCs can suppress the proliferation of B cells 
as well as natural killer cells (Corcione et al., 2006; Sotiropoulou et al., 2006). This suppression enhances the acute immune response to damage and can reduce a pro-fibrotic response that can result from sustained inflammation (Redd et al., 2004). Williams et al. tried to reduce scar sizes in ischemic cardiomyopathy through injection of allogeneic MSCs (Williams et al., 2013). The authors suggested that MSCs could reverse ventricular remodeling, and, indeed, it was shown that MSCs stimulate endogenous cardiac stem cells to proliferate and differentiate. The resulting mature cardiomyocytes exhibited therapeutic effect by secretion of growth factors and cytokines.

Similarly, $\mathrm{Li}$ et al. showed that MSCs loaded into a 3D graphene foam decreased scar tissue formation. The foam resulted in upregulation of VEGF as well as bFGF leading to enhanced neovascularization, as well as heightening levels of TGF- $\beta 3$, which prevents scarring. The MSC loaded foams were tested in vivo in a full-thickness wound model using wild-type rats. The use of MSCs in the foam resulted in a significant closure of the wound from day 3 post-wounding compared to controls of untreated and unloaded foam, this trend was observed consistently until endpoint at 14 Days post-wounding (Li et al., 2015).

With such obvious potential, it is not surprising that many researchers have explored the incorporation of stem cells like MSCs into electrospun nanofibers for wound and scar treatments. For example, Ma et al. integrated bone marrowderived MSCs (BM-MSCs) into nanofibers comprised of collagen and PLGA. The device demonstrated enhanced healing profiles in a full-thickness wound model in vivo using rats. The wounds treated with the BM-MSCs loaded nanofibers resulted in faster closure times compared to the untreated control, closing 8 days earlier (Ma et al., 2011). Furthermore, it was observed that localized treatment with the BM-MSCs resulted in a decrease in myofibroblast numbers. The authors postulated this may be due to MSCs ability to express hepatocyte growth factor 8 which inhibits myofibroblastic differentiation (Ma et al., 2011). These results suggest that this device would reduce scar tissue formation whilst allowing rapid and efficient wound repair.

In another study, Machula et al. electrospun nanofiber membranes of tropoelastin seeded with adipose-derived stem cells for wound healing applications (Machula et al., 2014). The authors found that the stem cells rapidly proliferated on the nanofibers and partook in efficient ECM establishment, covering the entire scaffold in vitro. Application of the cellnanofiber device in an in vivo excisional wound model with female SCID mice showed an enhancement in wound closure and restoration of normal epithelium compared to control wounds treated with petrolatum jelly-impregnated gauze. The average thickness of re-epithelized skin tissue for the control and stem cell-nanofiber treated groups was $27.7 \pm 7.8 \mu \mathrm{m}$ and $51.9 \pm$ $11.27 \mu \mathrm{m}$, respectively $(p=0.001)$. It is postulated by the authors that the electrospun tropoelastin device may persist within the scar tissue of healed skin and in doing so enhance the tensile strength of any resultant scar tissue.

A limitation associated with stem cell culture on electrospun nanofibers is that small pore size may result in a blockage in nutrient diffusion and cellular infiltration. If this problem can be mitigated, it could lead to a highly potent regenerative device.

\section{CONCLUSIONS AND FUTURE DIRECTIONS}

As detailed in this review, the use of electrospun nanofibers for scar treatment has substantial potential. With a plethora of polymers being "electrospinnable" alone or in conjunction with therapeutic agents or cells, the problem of scar management could be significantly improved. However, much work is still required to get such therapies into the clinic. Indeed, there are currently 5 clinical trials exploring the use of electrospun nanofibers ${ }^{6}$; yet, none of these are scar tissue-specific, and no current trials are recruiting. Conversely, there are 760 clinical trials listed for skin scarring ${ }^{7}, 140$ of which are recruiting ${ }^{8}$. This suggests that much research is focusing on novel therapies for scar treatment and prevention, which is a favorable scenario, and indeed these therapies if approved could in future be incorporated into electrospun nanofibers. Recent results have been notably discouraging. Metelimumab, for example, a TGF- $\beta 1$ targeting antibody, exhibited no improvement in the treatment of systemic sclerosis compared to a placebo control ${ }^{9}$. In saying this, an RNAi-based inhibitor of connective tissue growth factor (CTGF) termed RXI 109 has completed phase I trials and is now in phase II trials for hypertrophic scar treatment ${ }^{10}$. With promising therapies in the pipeline, it is exciting to hypothesize the efficiency of their delivery via electrospun nanofibers.

Encouragingly, electrospun nanofibers can be manufactured on an industrial scale, with the production of continuous nanofibers from a variety of polymers already proven (Ramachandran and Gouma, 2008; Zhang et al., 2012; Ma et al., 2015; Wang et al., 2018). Translating nanofiber production from laboratory to commercial scale is readily accommodated through the application of multi-jet nozzle electrospinners, which have been reported to process as much as $6.5 \mathrm{~kg} / \mathrm{h}$ of polymer to produce fibers (Persano et al., 2013). Current commercial examples include the Zeus Bioweb ${ }^{\mathrm{TM}}$ composites, composed of electrospun polytetrafluoroethylene (PTFE). The Bioweb ${ }^{\mathrm{TM}}$ exhibits a high surface area and possesses an advantageously minute pore size, typically in the range of $1-4 \mu \mathrm{m}$. Zeus boasts a variety of Bioweb ${ }^{\mathrm{TM}}$ applications including scaffold potential and implantable structures in the body ${ }^{11}$. A further commercial example of an electrospinning product is the SpinCare ${ }^{\mathrm{TM}}$ system by Nicast. SpinCare ${ }^{\mathrm{TM}}$ is a handheld device that fabricates nanofibers from polymers directly for tailored wound healing

\footnotetext{
${ }^{6} \mathrm{https} / /$ clinicaltrials.gov/ct2/results? cond=\&term=electrospinning\&cntry=\& state $=\&$ city $=\&$ dist $=\&$ Search $=$ Search $($ Date visited November 15, 2019).

${ }^{7}$ https://clinicaltrials.gov/ct2/results? cond=Skin+Scarring\&term $=\&$ cntry $=\&$ state $=\&$ city $=\&$ dist $=($ Date visited November 15,2019$)$.

${ }^{8} \mathrm{https} / / /$ clinicaltrials.gov/ct2/results? cond=Skin+Scarring\&Search=Apply\&recrs= a\&age_v=\&gndr=\&type $=\& r s l t=($ Date visited November 15,2019$)$.

${ }^{9} \mathrm{https://clinicaltrials.gov/ct2/show/NCT00432328}$

${ }^{10} \mathrm{https} / /$ clinicaltrials.gov/ct2/show/NCT02246465

${ }^{11} \mathrm{https}: / /$ www.zeusinc.com/products/biomaterials/bioweb-composites
} 
applications. These nanofibers provide a semi-permeable coverage facilitating excellent moisture regulation. The fibers are also comfortable as they are made to fit the shape of the patient's wound ${ }^{12}$.

It is well-believed that the combination of gene therapies with biomaterials hold great potential as future generation therapeutic devices (Bleiziffer et al., 2007; Goker et al., 2019). Although promising, gene therapy is not without limitations. For example, therapies of this nature are historically challenging to deliver into cells, due to similarities in charges between nucleic acids and cell membranes. Viral gene delivery is the most common form of gene therapy due to its high efficiency. These vectors, however, are met with numerous trepidations as they can result in mutagenesis and have a restricted capacity for genetic material (Mingozzi and High, 2013). Non-viral options for gene therapy also exist and include cationic polymers (Olden et al., 2018), liposomes (Balazs and Godbey, 2011), and peptides (McCarthy et al., 2014; Cole et al., 2019). Indeed, recent literature published by Mulholland et al. explored the delivery of an siRNA complexed with a cell penetrating peptide termed RALA from an electrospun bilayer wound patch. The use of the RALA peptide significantly enhanced the transfection efficient of the nucleic acids in vitro using HMEC-1 endothelial cells, downregulating expression anti-angiogenic FK506-binding protein-like FKBPL. This high

$\overline{{ }^{12} \mathrm{http} / / / \text { nicast.com/spincare/product-description/ }}$

\section{REFERENCES}

Acevedo, C. A., Sánchez, E., Orellana, N., Morales, P., Olguín, Y., Brown, D. I., et al. (2019). Re-epithelialization appraisal of skin wound in a porcine model using a salmon-gelatin based biomaterial as wound dressing. Pharmaceutics 11:196. doi: 10.3390/pharmaceutics11050196

Aderibigbe, B. A., and Buyana, B. (2018). Alginate in wound dressings. Pharmaceutics 10:42. doi: 10.3390/pharmaceutics10020042

Anjum, F., Agabalyan, N. A., Sparks, H. D., Rosin, N. L., Kallos, M. S., and Biernaskie, J. (2017). Biocomposite nanofiber matrices to support ECM remodeling by human dermal progenitors and enhanced wound closure. Sci. Rep. 7:10291. doi: 10.1038/s41598-017-10735-x

Aranaz, I., Mengibar, M., Harris, R., Panos, I., Miralles, B., Acosta, N., et al. (2009). Functional characterization of chitin and chitosan. Curr. Chem. Biol. 3, 203-230. doi: 10.2174/187231309788166415

Atiyeh, B. S., Amm, C. A., and El Musa, K. A. (2003). Improved scar quality following primary and secondary healing of cutaneous wounds. Aesthetic Plast. Surg. 27, 411-417. doi: 10.1007/s00266-003-3049-3

Atkinson, J.-A. M., McKenna, K. T., Barnett, A. G., McGrath, D. J., and Rudd, M. (2005). A randomized, controlled trial to determine the efficacy of paper tape in preventing hypertrophic scar formation in surgical incisions that traverse Langer's skin tension lines. Plast. Reconstr. Surg. 116, 1648-1656; discussion 1657-1658. doi: 10.1097/01.prs.0000187147.73963.a5

Baker, S. C., Atkin, N., Gunning, P. A., Granville, N., Wilson, K., Wilson, D., et al. (2006). Characterisation of electrospun polystyrene scaffolds for three-dimensional in vitro biological studies. Biomaterials 27, 3136-3146. doi: 10.1016/j.biomaterials.2006.01.026

Balazs, D. A., and Godbey, W. (2011). Liposomes for use in gene delivery. J. Drug Deliv. 2011, 1-12. doi: 10.1155/2011/326497

Barnes, L. A., Marshall, C. D., Leavitt, T., Hu, M. S., Moore, A. L., Gonzalez, J. G., et al. (2018). Mechanical forces in cutaneous wound healing: emerging therapies to minimize scar formation. Adv. Wound Care 7, 47-56. doi: 10.1089/wound.2016.0709 efficiency translated to significant upsurge in angiogenic activity in vivo in wounds on the backs of C57BL/6 mice, resulting in an increase in blood vessel density of $326 \%$ compared to untreated wounds (Mulholland et al., 2019). This technology holds excellent potential for scar tissue treatment as a vast array of nucleic acids could be delivered in this manner.

Taken together, with the literature and the state-of-the-art technology discussed in this review, it can be rationalized that electrospinning shows great promise for the development of next generation devices for the treatment and management of scars.

\section{AUTHOR'S NOTE}

This manuscript was an invited paper for the article collection on Biomaterials for Skin Wound Repair: Tissue Engineering, Guided Regeneration, and Wound Scarring Prevention.

\section{AUTHOR CONTRIBUTIONS}

EM wrote the manuscript and produced all figures and tables with the aid of SMART Servier Medical Art www.smart.servier.com (Attribution 3.0 Unported (CC BY 3.0).

\section{ACKNOWLEDGMENTS}

I would like to thank Dr. James Illingworth for his constant support in the writing of this article.

Basar, A. O., Castro, S., Torres-Giner, S., Lagaron, J. M., and Turkoglu Sasmazel, H. (2017). Novel poly( $\varepsilon$-caprolactone)/gelatin wound dressings prepared by emulsion electrospinning with controlled release capacity of Ketoprofen anti-inflammatory drug. Mater. Sci. Eng. C 81, 459-468. doi: 10.1016/j.msec.2017.08.025

Bazmandeh, A. Z., Mirzaei, E., Ghasemi, Y., and Kouhbanani, M. A. J. (2019). Hyaluronic acid coated electrospun chitosan-based nanofibers prepared by simultaneous stabilizing and coating. Int. J. Biol. Macromol. 138, 403-411. doi: 10.1016/j.ijbiomac.2019.07.107

Berman, B., Maderal, A., and Raphael, B. (2017). Keloids and hypertrophic scars: pathophysiology, classification, and treatment. Dermatol. Surg. 43(Suppl. 1), S3-S18. doi: 10.1097/DSS.0000000000000819

Bhardwaj, N., and Kundu, S. C. (2010). Electrospinning: a fascinating fiber fabrication technique. Biotechnol. Adv. 28, 325-347. doi: 10.1016/j.biotechadv.2010.01.004

Bleiziffer, O., Eriksson, E., Yao, F., Horch, R. E., and Kneser, U. (2007). Gene transfer strategies in tissue engineering. J. Cell. Mol. Med. 11, 206-223. doi: 10.1111/j.1582-4934.2007.00027.x

Bonvallet, P. P., Culpepper, B. K., Bain, J. L., Schultz, M. J., Thomas, S. J., and Bellis, S. L. (2014). Microporous dermal-like electrospun scaffolds promote accelerated skin regeneration. Tissue Eng. Part A 20, 2434-2445. doi: 10.1089/ten.tea.2013.0645

Broughton, G., Janis, J. E., and Attinger, C. E. (2006). Wound healing: an overview. Plast. Reconstr. Surg. $117(7$ Suppl.), 1e-S-32e-S. doi: 10.1097/01.prs.0000222562.60260.f9

Burdick, J. A., Mauck, R. L., and Gerecht, S. (2016). To serve and protect: hydrogels to improve stem cell-based therapies. Cell Stem Cell 18, 13-15. doi: 10.1016/j.stem.2015.12.004

Caley, M. P., Martins, V. L. C., and O’Toole, E. A. (2015). Metalloproteinases and wound healing. Adv. Wound Care 4, 225-234. doi: 10.1089/wound. 2014.0581

Campos, P. M. B. G. M., Ricci, G., Semprini, M., and Lopes, R. A. (1999). Histopathological, morphometric, and stereologic studies of dermocosmetic 
skin formulations containing vitamin a and/or glycolic acid. J. Cosmet. Sci. $50,159-70$.

Carswell, L., and Borger, J. (2019). Hypertrophic scarring keloids. StatPearls.

Chen, M., Patra, P. K., Lovett, M. L., Kaplan, D. L., and Bhowmick, S. (2009). Role of electrospun fibre diameter and corresponding specific surface area (SSA) on cell attachment. J. Tissue Eng. Regen. Med. 3, 269-279. doi: 10.1002/ term. 163

Cheng, G., Yin, C., Tu, H., Jiang, S., Wang, Q., Zhou, X., et al. (2019). Controlled co-delivery of growth factors through layer-by-layer assembly of core-shell nanofibers for improving bone regeneration. ACS Nano 13, 6372-6382. doi: 10.1021/acsnano.8b06032

Chua, K.-N., Chai, C., Lee, P.-C., Tang, Y.-N., Ramakrishna, S., Leong, K. W., et al. (2006). Surface-aminated electrospun nanofibers enhance adhesion and expansion of human umbilical cord blood hematopoietic stem/progenitor cells. Biomaterials 27, 6043-6051. doi: 10.1016/j.biomaterials.2006.06.017

Cole, G., Ali, A. A., McErlean, E., Mulholland, E. J., Short, A., McCrudden, C. M., et al. (2019). DNA vaccination via RALA nanoparticles in a microneedle delivery system induces a potent immune response against the endogenous prostate cancer stem cell antigen. Acta Biomater. 96, 480-490. doi: 10.1016/j.actbio.2019.07.003

Commander, S., Chamata, E., Cox, J., Dickey, R., and Lee, E. (2016). Update on postsurgical scar management. Semin. Plast. Surg. 30, 122-128. doi: $10.1055 / \mathrm{s}-0036-1584824$

Corcione, A., Benvenuto, F., Ferretti, E., Giunti, D., Cappiello, V., Cazzanti, F., et al. (2006). Human mesenchymal stem cells modulate B-cell functions. Blood 107, 367-372. doi: 10.1182/blood-2005-07-2657

Corr, D. T., Gallant-Behm, C. L., Shrive, N. G., and Hart, D. A. (2009). Biomechanical behavior of scar tissue and uninjured skin in a porcine model. Wound Repair Regen. 17, 250-259. doi: 10.1111/j.1524-475X.2009.00463.x

Cui, W., Li, X., Zhou, S., and Weng, J. (2007). Investigation on process parameters of electrospinning system through orthogonal experimental design. J. Appl. Polym. Sci. 103, 3105-3112. doi: 10.1002/app.25464

Darby, I. A., Laverdet, B., Bonté, F., and Desmoulière, A. (2014). Fibroblasts and myofibroblasts in wound healing. Clin. Cosmet. Investig. Dermatol. 7, 301-311. doi: $10.2147 / C C I D . S 50046$

Deng, A., Yang, Y., Du, S., and Yang, S. (2018). Electrospinning of in situ crosslinked recombinant human collagen peptide/chitosan nanofibers for wound healing. Biomater. Sci. 6, 2197-2208. doi: 10.1039/C8BM00492G

Desmoulière, A., Chaponnier, C., and Gabbiani, G. (2005). Tissue repair, contraction, and the myofibroblast. Wound Repair Regen. 13, 7-12. doi: $10.1111 / j .1067-1927.2005 .130102 . x$

Dunn, L., Prosser, H. C. G., Tan, J. T. M., Vanags, L. Z., Ng, M. K. C., Bursill, C. A. (2013). Murine Model of Wound Healing. J. Vis. Exp. e50265. doi: $10.3791 / 50265$

Ehrlich, H. P., Desmoulière, A., Diegelmann, R. F., Cohen, I. K., Compton, C. C., Garner, W. L., et al. (1994). Morphological and immunochemical differences between keloid and hypertrophic scar. Am. J. Pathol. 145, 105-113.

Fang, R. C., and Galiano, R. D. (2008). A review of becaplermin gel in the treatment of diabetic neuropathic foot ulcers. Biologics 2, 1-12. doi: 10.2147/BTT.S1338

Field, C. K., and Kerstein, M. D. (1994). Overview of wound healing in a moist environment. Am. J. Surg. 167, S2-S6. doi: 10.1016/0002-9610(94) 90002-7

Fu, X.-B., Sun, T.-Z., Li, X.-K., and Sheng, Z.-Y. (2005). Morphological and distribution characteristics of sweat glands in hypertrophic scar and their possible effects on sweat gland regeneration. Chin. Med. J. 118, 186-191.

Gao, W., Jin, W., Li, Y., Wan, L., Wang, C., Lin, C., et al. (2017). A highly bioactive bone extracellular matrix-biomimetic nanofibrous system with rapid angiogenesis promotes diabetic wound healing. J. Mater. Chem. B 5, 7285-7296. doi: $10.1039 / \mathrm{C} 7 \mathrm{~TB} 01484 \mathrm{H}$

Gassner, H. G., Sherris, D. A., and Otley, C. C. (2000). Treatment of facial wounds with botulinum toxin A improves cosmetic outcome in primates. Plast. Reconstr. Surg. 105, 1948-1953. doi: 10.1097/00006534-200005000-00005

Geng, X., Kwon, O., and Jang, J. (2005). Electrospinning of chitosan dissolved in concentrated acetic acid solution. Biomaterials 26, 5427-5432. doi: 10.1016/j.biomaterials.2005.01.066

Ghosh, P., Han, G., De, M., Kim, C. K., and Rotello, V. M. (2008). Gold nanoparticles in delivery applications. Adv. Drug Deliv. Rev. 60, 1307-1315. doi: 10.1016/j.addr.2008.03.016
Goker, F., Larsson, L., Del Fabbro, M., and Asa'ad, F. (2019). Gene delivery therapeutics in the treatment of periodontitis and peri-implantitis: a state of the art review. Int. J. Mol. Sci. 20:3551. doi: 10.3390/ijms20143551

Golecki, H. M., Yuan, H., Glavin, C., Potter, B., Badrossamay, M. R., Goss, J. A., et al. (2014). Effect of solvent evaporation on fiber morphology in rotary jet spinning. Langmuir 30, 13369-13374. doi: 10.1021/la5023104

Grove, G. L., and Kligman, A. M. (1983). Age-associated changes in human epidermal cell renewal. J. Gerontol. 38, 137-142. doi: 10.1093/geronj/38.2.137

Gu, X., Cao, R., Li, Y., Liu, S., Wang, Z., Feng, S., et al. (2019). Threecomponent antibacterial membrane of poly(butylene carbonate), poly(lactic acid) and chitosan prepared by electrospinning. Mater. Technol. 34, 463-470. doi: 10.1080/10667857.2019.1576822

Hadjizadeh, A., Ghasemkhah, F., and Ghasemzaie, N. (2017). Polymeric scaffold based gene delivery strategies to improve angiogenesis in tissue engineering: a review. Polym. Rev. 57, 505-556. doi: 10.1080/15583724.2017.1292402

Haider, A., Haider, S., and Kang, I.-K. (2015). A comprehensive review summarizing the effect of electrospinning parameters and potential applications of nanofibers in biomedical and biotechnology. Arab. J. Chem. 11, 1165-1188. doi: 10.1016/j.arabjc.2015.11.015

Hajiali, H., Summa, M., Russo, D., Armirotti, A., Brunetti, V., Bertorelli, R., et al. (2016). Alginate-lavender nanofibers with antibacterial and anti-inflammatory activity to effectively promote burn healing. J. Mater. Chem. B 4, 1686-1695. doi: $10.1039 /$ C5TB02174J

He, C.-L., Huang, Z.-M., and Han, X.-J. (2009). Fabrication of drug-loaded electrospun aligned fibrous threads for suture applications. J. Biomed. Mater. Res. Part A 89A, 80-95. doi: 10.1002/jbm.a.32004

He, S., Xia, T., Wang, H., Wei, L., Luo, X., and Li, X. (2012). Multiple release of polyplexes of plasmids VEGF and bFGF from electrospun fibrous scaffolds towards regeneration of mature blood vessels. Acta Biomater. 8, 2659-2669. doi: 10.1016/j.actbio.2012.03.044

He, W., Ma, Z., Yong, T., Teo, W. E., and Ramakrishna, S. (2005). Fabrication of collagen-coated biodegradable polymer nanofiber mesh and its potential for endothelial cells growth. Biomaterials 26, 7606-7615. doi: 10.1016/j.biomaterials.2005.05.049

Hsieh, J. Y., Smith, T. D., Meli, V. S., Tran, T. N., Botvinick, E. L., and Liu, W. F. (2017). Differential regulation of macrophage inflammatory activation by fibrin and fibrinogen. Acta Biomater. 47, 14-24. doi: 10.1016/j.actbio.2016.09.024

Hu, M. S., Cheng, J., Borrelli, M. R., Leavitt, T., Walmsley, G. G., Zielins, E. R., et al. (2018). An improved humanized mouse model for excisional wound healing using double transgenic mice. Adv. Wound Care 7, 11-17. doi: 10.1089 /wound.2017.0772

Ignatova, M., Starbova, K., Markova, N., Manolova, N., and Rashkov, I. (2006). Electrospun nano-fibre mats with antibacterial properties from quaternised chitosan and poly(vinyl alcohol). Carbohydr. Res. 341, 2098-2107. doi: 10.1016/j.carres.2006.05.006

Im, J. S., Yun, J., Lim, Y.-M., Kim, H.-I., and Lee, Y.-S. (2010). Fluorination of electrospun hydrogel fibers for a controlled release drug delivery system. Acta Biomater. 6, 102-109. doi: 10.1016/j.actbio.2009.06.017

Jackson, B. A., and Shelton, A. J. (1999). Pilot study evaluating topical onion extract as treatment for postsurgical scars. Dermatol. Surg. 25, 267-269. doi: 10.1046/j.1524-4725.1999.08240.x

Jackson, W. M., Nesti, L. J., and Tuan, R. S. (2012). Mesenchymal stem cell therapy for attenuation of scar formation during wound healing. Stem Cell Res. Ther. 3:20. doi: 10.1186/scrt111

Jeong, K.-J., Song, Y., Shin, H.-R., Kim, J. E., Kim, J., Sun, F., et al. (2017). In vivo study on the biocompatibility of chitosan-hydroxyapatite film depending on degree of deacetylation. J. Biomed. Mater. Res. Part A 105, 1637-1645. doi: 10.1002/jbm.a.35993

Jiang, H., Wang, L., and Zhu, K. (2014). Coaxial electrospinning for encapsulation and controlled release of fragile water-soluble bioactive agents. J. Control Release 193, 296-303. doi: 10.1016/j.jconrel.2014.04.025

Ju, H. W., Lee, O. J., Lee, J. M., Moon, B. M., Park, H. J., Park, Y. R., et al. (2016). Wound healing effect of electrospun silk fibroin nanomatrix in burn-model. Int. J. Biol. Macromol. 85, 29-39. doi: 10.1016/j.ijbiomac.2015. 12.055

Karami, Z., Rezaeian, I., Zahedi, P., and Abdollahi, M. (2013). Preparation and performance evaluations of electrospun poly( $\varepsilon$-caprolactone), poly(lactic acid), and their hybrid (50/50) nanofibrous mats containing thymol as an 
herbal drug for effective wound healing. J. Appl. Polym. Sci. 129, 756-766. doi: $10.1002 /$ app. 38683

Kean, T., and Thanou, M. (2010). Biodegradation, biodistribution and toxicity of chitosan. Adv. Drug Deliv. Rev. 62, 3-11. doi: 10.1016/j.addr.2009.09.004

Kiani, M. T., Higgins, C. A., and Almquist, B. D. (2018). The Hair follicle: an underutilized source of cells and materials for regenerative medicine. ACS Biomater. Sci. Eng. 4, 1193-1207. doi: 10.1021/acsbiomaterials.7b00072

Koh, H. S., Yong, T., Chan, C. K., and Ramakrishna, S. (2008). Enhancement of neurite outgrowth using nano-structured scaffolds coupled with laminin. Biomaterials 29, 3574-3582. doi: 10.1016/j.biomaterials.2008.05.014

Kordestani, S. S. (2019). "Wound care management," in Atlas of Wound Healing (Elsevier), 31-47. Available online at: https://linkinghub.elsevier.com/retrieve/ pii/B9780323679688000057

Krafts, K. P. (2010). Tissue repair: the hidden drama. Organogenesis 6, 225-233. doi: 10.4161/org.6.4.12555

Kryczka, J., and Boncela, J. (2015). Leukocytes: the double-edged sword in fibrosis. Mediators Inflamm. 2015, 1-10. doi: 10.1155/2015/652035

Lagaron, J. M., Solouk, A., Castro, S., and Echegoyen, Y. (2017). "Biomedical applications of electrospinning, innovations, and products," in Electrospun Materials for Tissue Engineering and Biomedical Applications, eds T. Uyar and E. Kny (Elsevier; Woodhead Publishing), 57-72. doi: 10.1016/B978-0-08-101022-8.00010-7

Li, B., and Wang, J. H.-C. (2011). Fibroblasts and myofibroblasts in wound healing: force generation and measurement. J. Tissue Viability 20, 108-120. doi: 10.1016/j.jtv.2009.11.004

Li, Z., Wang, H., Yang, B., Sun, Y., and Huo, R. (2015). Three-dimensional graphene foams loaded with bone marrow derived mesenchymal stem cells promote skin wound healing with reduced scarring. Mater. Sci. Eng. C 57, 181-188. doi: 10.1016/j.msec.2015.07.062

Liao, Y., Zhang, L., Gao, Y., Zhu, Z.-T., and Fong, H. (2009). Preparation, characterization, and encapsulation/release studies of a composite nanofiber mat electrospun from an emulsion containing poly (lactic-co-glycolic acid). Polymer 49, 5294-5299. doi: 10.1016/j.polymer.2008.09.045

Lim, X., Tateya, I., Tateya, T., Muñoz-Del-Río, A., and Bless, D. M. (2006). Immediate inflammatory response and scar formation in wounded vocal folds. Ann. Otol. Rhinol. Laryngol. 115, 21-929. doi: 10.1177/000348940611 501212

Longaker, M. T., Gurtner, G. C., Werner, S., and Barrandon, Y. (2008). Wound repair and regeneration. Nature 453, 314-321. doi: 10.1038/nature07039

Ma, K., Liao, S., He, L., Lu, J., Ramakrishna, S., and Chan, C. K. (2011). Effects of nanofiber/stem cell composite on wound healing in acute full-thickness skin wounds. Tissue Eng. Part A 17, 1413-1424. doi: 10.1089/ten.tea.2010.0373

Ma, L., Yang, G., Wang, N., Zhang, P., Guo, F., Meng, J., et al. (2015). Trap effect of three-dimensional fibers network for high efficient cancer-cell capture. Adv. Healthc. Mater. 4, 838-843. doi: 10.1002/adhm.201400650

Machula, H., Ensley, B., and Kellar, R. (2014). Electrospun tropoelastin for delivery of therapeutic adipose-derived stem cells to full-thickness dermal wounds. Adv. Wound Care 3, 367-375. doi: 10.1089/wound.2013.0513

Mackool, R. J., Gittes, G. K., and Longaker, M. T. (1998). Scarless healing. The fetal wound. Clin. Plast. Surg. 25, 357-365.

Mahjour, S. B., Fu, X., Yang, X., Fong, J., Sefat, F., and Wang, H. (2015). Rapid creation of skin substitutes from human skin cells and biomimetic nanofibers for acute full-thickness wound repair. Burns 41, 1764-1774. doi: 10.1016/j.burns.2015.06.011

Marshall, C. D., Hu, M. S., Leavitt, T., Barnes, L. A., Lorenz, H. P., and Longaker, M. T. (2018). Cutaneous scarring: basic science, current treatments, and future directions. Adv. Wound Care 7, 29-45. doi: 10.1089/wound.2016.0696

Martinello, T., Gomiero, C., Perazzi, A., Iacopetti, I., Gemignani, F., DeBenedictis, G. M., et al. (2018). Allogeneic mesenchymal stem cells improve the wound healing process of sheep skin. BMC Vet. Res. 14:202. doi: 10.1186/s12917-018-1527-8

Mashhadi, S. A., and Loh, C. Y. Y. (2011). A knotless method of securing the subcuticular suture. Aesthetic Surg. J. 31, 594-595. doi: $10.1177 / 1090820 \mathrm{X} 11411080$

McCarthy, H. O., McCaffrey, J., McCrudden, C. M., Zholobenko, A., Ali, A. A., McBride, J. W., et al. (2014). Development and characterization of selfassembling nanoparticles using a bio-inspired amphipathic peptide for gene delivery. J. Control Release 189, 141-149. doi: 10.1016/j.jconrel.2014.06.048
Mengistu Lemma, S., Bossard, F., and Rinaudo, M. (2016). Preparation of pure and stable chitosan nanofibers by electrospinning in the presence of poly(ethylene oxide). Int. J. Mol. Sci. 17:1790. doi: 10.3390/ijms17111790

Mingozzi, F., and High, K. A. (2013). Immune responses to AAV vectors: overcoming barriers to successful gene therapy. Blood 122, 23-36. doi: 10.1182/blood-2013-01-306647

Mirastschijski, U., Sander, J. T., Zier, U., Rennekampff, H. O., Weyand, B., and Vogt, P. M. (2015). The cost of post-burn scarring. Ann. Burns Fire Disasters $28,215-222$.

Monaco, J. L., and Lawrence, W. T. (2003). Acute wound healing an overview. Clin. Plast. Surg. 30, 1-12. doi: 10.1016/S0094-1298(02)00070-6

Montagna, W., and Yun, J. S. (1964). The skin of the domestic pig. J. Invest. Dermatol. 42, 11-21. doi: 10.1038/jid.1964.110

Mulholland, E. J., Ali, A., Robson, T., Dunne, N. J., and McCarthy, H. O. (2019). Delivery of RALA/siFKBPL nanoparticles via electrospun bilayer nanofibres: an innovative angiogenic therapy for wound repair. J. Control Release. 316, 53-65. doi: 10.1016/j.jconrel.2019.10.050

Nie, H., He, A., Zheng, J., Xu, S., Li, J., and Han, C. C. (2008). Effects of chain conformation and entanglement on the electrospinning of pure alginate. Biomacromolecules 9, 1362-1365. doi: 10.1021/bm701349j

Olden, B. R., Cheng, Y., Yu, J. L., and Pun, S. H. (2018). Cationic polymers for non-viral gene delivery to human T cells. J. Control Release 282, 140-147 doi: 10.1016/j.jconrel.2018.02.043

Orbay, H., Tobita, M., and Mizuno, H. (2012). Mesenchymal stem cells isolated from adipose and other tissues: basic biological properties and clinical applications. Stem Cells Int. 2012:461718. doi: 10.1155/2012/461718

Park, K., Ju, Y. M., Son, J. S., Ahn, K.-D., and Han, D. K. (2007). Surface modification of biodegradable electrospun nanofiber scaffolds and their interaction with fibroblasts. J. Biomater. Sci. Polym. Ed. 18, 369-382. doi: $10.1163 / 156856207780424997$

Persano, L., Camposeo, A., Tekmen, C., and Pisignano, D. (2013). Industrial upscaling of electrospinning and applications of polymer nanofibers: a review. Macromol. Mater. Eng. 298, 504-520. doi: 10.1002/mame.201200290

Prabhakaran, M. P., Venugopal, J., Chan, C. K., and Ramakrishna, S. (2008). Surface modified electrospun nanofibrous scaffolds for nerve tissue engineering. Nanotechnology 19:455102. doi: 10.1088/0957-4484/19/45/455102

Qin, Y. (2016). (Ed.). “Functional wound dressings," in Woodhead Publishing Series in Textiles, Medical Textile Materials (Elsevier; Woodhead Publishing), 89-107. doi: 10.1016/B978-0-08-100618-4.00007-8

Quinn, J. A., Yang, Y., Buffington, A. N., Romero, F. N., and Green, M. D. (2018). Preparation and characterization of crosslinked electrospun poly(vinyl alcohol) nanofibrous membranes. Polymer 134, 275-281. doi: 10.1016/j.polymer.2017.11.023

Ramachandran, K., and Gouma, P.-I. (2008). Electrospinning for bone tissue engineering. Recent Pat. Nanotechnol. 2, 1-7. doi: 10.2174/187221008783478608

Ramakrishna, S., Fujihara, K., Teo, W.-E., Yong, T., Ma, Z., and Ramaseshan, R. (2006). Electrospun nanofibers: solving global issues. Mater. Today 9, 40-50. doi: 10.1016/S1369-7021(06)71389-X

Ramirez, H., Patel, S. B., and Pastar, I. (2014). The role of TGF $\beta$ signaling in wound epithelialization. Adv. Wound Care 3, 482-491. doi: 10.1089/wound.2013.0466

Ramotowski, C., Qu, X., and Villa-Diaz, L. G. (2019). Progress in the use of induced pluripotent stem cell-derived neural cells for traumatic spinal cord injuries in animal populations: meta-analysis and review. Stem Cells Transl. Med. 8, 681-693. doi: 10.1002/sctm.18-0225

Redd, M. J., Cooper, L., Wood, W., Stramer, B., and Martin, P. (2004). Wound healing and inflammation: embryos reveal the way to perfect repair. Philos. Trans. R. Soc. Lond. B Biol. Sci. 359, 777-784. doi: 10.1098/rstb.2004.1466

REGRANEX $®$ (2018). REGRANEX® (Becaplermin) Gel for Topical Use. Highlights of Prescribing Information.

Reiber, G. E., Vileikyte, L., Boyko, E. J., del Aguila, M., Smith, D. G., Lavery, L. A., et al. (1999). Causal pathways for incident lower-extremity ulcers in patients with diabetes from two settings. Diabetes Care 22, 157-162. doi: 10.2337/diacare.22.1.157

Ren, G., Zhang, L., Zhao, X., Xu, G., Zhang, Y., Roberts, A. I., et al. (2008). Mesenchymal stem cell-mediated immunosuppression occurs via concerted action of chemokines and nitric oxide. Cell Stem Cell 2, 141-150. doi: $10.1016 /$ j.stem.2007.11.014 
Sá, O., Lopes, N., Alves, M., and Caran, E. (2018). Effects of glycine on collagen, PDGF, and EGF expression in model of oral mucositis. Nutrients 10:1485. doi: $10.3390 /$ nu10101485

Sarrazy, V., Billet, F., Micallef, L., Coulomb, B., and Desmoulière, A. (2011). Mechanisms of pathological scarring: role of myofibroblasts and current developments. Wound Repair Regen. 19(Suppl. 1), s10-s15. doi: 10.1111/j.1524-475X.2011.00708.x

Schilling, J. A. (1976). Wound healing. Surg. Clin. North Am. 56, 859-874. doi: 10.1016/S0039-6109(16)40983-7

Seaton, M., Hocking, A., and Gibran, N. S. (2015). Porcine models of cutaneous wound healing. ILAR J. 56, 127-138. doi: 10.1093/ilar/ilv016

Sencadas, V., Ribeiro, C., Nunes-Pereira, J., Correia, V., and LancerosMéndez, S. (2012). Fiber average size and distribution dependence on the electrospinning parameters of poly(vinylidene fluoride-trifluoroethylene) membranes for biomedical applications. Appl. Phys. A 109, 685-691. doi: 10.1007/s00339-012-7101-5

Sequeira, R. S., Miguel, S. P., Cabral, C. S. D., Moreira, A. F., Ferreira, P., and Correia, I. J. (2019). Development of a Poly(vinyl alcohol)/Lysine electrospun membrane-based drug delivery system for improved skin regeneration. Int. J. Pharm. 570:118640. doi: 10.1016/j.ijpharm.2019.118640

Shalumon, K. T., Anulekha, K. H., Nair, S. V., Nair, S. V., Chennazhi, K. P., and Jayakumar, R. (2011). Sodium alginate/poly(vinyl alcohol)/nano $\mathrm{ZnO}$ composite nanofibers for antibacterial wound dressings. Int. J. Biol. Macromol. 49, 247-254. doi: 10.1016/j.ijbiomac.2011.04.005

Shan, Y.-H., Peng, L.-H., Liu, X., Chen, X., Xiong, J., and Gao, J.-Q. (2015). Silk fibroin/gelatin electrospun nanofibrous dressing functionalized with astragaloside IV induces healing and anti-scar effects on burn wound. Int. J. Pharm. 479, 291-301. doi: 10.1016/j.ijpharm.2014.12.067

Shete, A. S., Yadav, A. V., and Murthy, S. M. (2012). Chitosan and chitosan chlorhydrate based various approaches for enhancement of dissolution rate of carvedilol. Daru 20:93. doi: 10.1186/2008-2231-20-93

Singer, A. J., and Clark, R. A. F. (1999). Cutaneous wound healing. N. Engl. J. Med. 341, 738-746. doi: 10.1056/NEJM199909023411006

Sotiropoulou, P. A., Perez, S. A., Gritzapis, A. D., Baxevanis, C. N., and Papamichail, M. (2006). Interactions between human mesenchymal stem cells and natural killer cells. Stem Cells 24, 74-85. doi: 10.1634/stemcells.2004-0359

Storch, J. E., and Rice, J. (eds.). (2005). Reconstructive Plastic Surgical Nursing. Oxford: Blackwell Publishing Ltd. doi: 10.1002/9780470774656

Tanaka, A., Hatoko, M., Tada, H., Iioka, H., Niitsuma, K., and Miyagawa, S. (2004). Expression of p53 family in scars. J. Dermatol. Sci. 34, 17-24. doi: 10.1016/j.jdermsci.2003.09.005

Tarun, K., and Gobi, N. (2012). Calcium alginate/PVA blended nano fibre matrix for wound dressing. Indian J. Fibre Text Res. 37, 127-132.

Thomas, J. R., and Somenek, M. (2012). Scar revision review. Arch. Facial Plast. Surg. 14:162. doi: 10.1001/archfacial.2012.223

van Zuijlen, P. P. M., Ruurda, J. J. B., van Veen, H. A., van Marle, J., van Trier, A. J. M., Groenevelt, F., et al. (2003). Collagen morphology in human skin and scar tissue: no adaptations in response to mechanical loading at joints. Burns 29, 423-431. doi: 10.1016/S0305-4179(03)00052-4

Venkat, P., Shen, Y., Chopp, M., and Chen, J. (2018). Cell-based and pharmacological neurorestorative therapies for ischemic stroke. Neuropharmacology 134, 310-322. doi: 10.1016/j.neuropharm.2017.08.036

Wakuda, Y., Nishimoto, S., Suye, S., and Fujita, S. (2018). Native collagen hydrogel nanofibres with anisotropic structure using core-shell electrospinning. Sci. Rep. 8:6248. doi: 10.1038/s41598-018-24700-9

Wang, L., Yang, J., Ran, B., Yang, X., Zheng, W., Long, Y., et al. (2017). Small molecular TGF- $\beta 1$-inhibitor-loaded electrospun fibrous scaffolds for preventing hypertrophic scars. ACS Appl. Mater. Interfaces 9, 32545-32553. doi: 10.1021/acsami.7b09796

Wang, M., Xiao, Y., Lin, L., Zhu, X., Du, L., and Shi, X. (2018). A microfluidic chip integrated with hyaluronic acid-functionalized electrospun chitosan nanofibers for specific capture and nondestructive release of CD44overexpressing circulating tumor cells. Bioconjug. Chem. 29, 1081-1090. doi: 10.1021/acs.bioconjchem.7b00747

Wang, X., Ge, J., Tredget, E. E., and Wu, Y. (2013). The mouse excisional wound splinting model, including applications for stem cell transplantation. Nat. Protoc. 8, 302-309. doi: 10.1038/nprot.2013.002

Wei, Q., Xu, F., Xu, X., Geng, X., Ye, L., Zhang, A., et al. (2016). The multifunctional wound dressing with core-shell structured fibers prepared by coaxial electrospinning. Front. Mater. Sci. 10, 113-121. doi: 10.1007/s11706-016-0339-7

Werner, S., and Grose, R. (2003). Regulation of wound healing by growth factors and cytokines. Physiol. Rev. 83, 835-870. doi: 10.1152/physrev.2003.83. 3.835

White, W., Brody, G. S., Glaser, A. A., Marangoni, R. D., Beckwith, T. G., Must, J. S., et al. (1971). Tensiometric studies of unwounded and wounded skin. Ann. Surg. 173, 19-25. doi: 10.1097/00000658-197101000-00003

Williams, A. R., Suncion, V. Y., McCall, F., Guerra, D., Mather, J., Zambrano, J. P., et al. (2013). Durable scar size reduction due to allogeneic mesenchymal stem cell therapy regulates whole-chamber remodeling. J. Am. Heart Assoc. 2:e000140. doi: 10.1161/JAHA.113.000140

Wu, J., and Hong, Y. (2016). Enhancing cell infiltration of electrospun fibrous scaffolds in tissue regeneration. Bioact. Mater. 1, 56-64. doi: 10.1016/j.bioactmat.2016.07.001

Xie, Q., Jia, L., Xu, H., Hu, X., Wang, W., and Jia, J. (2016). Fabrication of core-shell PEI/pBMP2-PLGA electrospun scaffold for gene delivery to periodontal ligament stem cells. Stem Cells Int. 2016, 1-11. doi: 10.1155/2016/ 5385137

Yan, D., Jones, J., Yuan, X., Xu, X., Sheng, J., Lee, J. C. M., et al. (2013). Plasma treatment of random and aligned electrospun PCL nanofibers. J. Med. Biol. Eng. 33, 171-178. doi: 10.5405/jmbe.1072

Yang, X., Yang, J., Wang, L., Ran, B., Jia, Y., Zhang, L., et al. (2017). Pharmaceutical intermediate-modified gold nanoparticles: against multidrug-resistant bacteria and wound-healing application via an electrospun scaffold. ACS Nano 11, 5737-5745. doi: 10.1021/acsnano.7b01240

Yang, X. H., Xiao, Y. Y., Tan, T. X., Luo, J. J., Fan, P. J., and Lei, S. R. (2016). C-jun is increased in hypertrophic scar and inhibits apoptosis in fibroblasts. Int. J. Clin. Exp. Med. 9, 3132-3138.

Yang, Y., Xia, T., Chen, F., Wei, W., Liu, C., He, S., et al. (2012). Electrospun fibers with plasmid bFGF polyplex loadings promote skin wound healing in diabetic rats. Mol. Pharm. 9, 48-58. doi: 10.1021/mp200246b

Younes, I., Frachet, V., Rinaudo, M., Jellouli, K., and Nasri, M. (2016). Cytotoxicity of chitosans with different acetylation degrees and molecular weights on bladder carcinoma cells. Int. J. Biol. Macromol. 84, 200-207. doi: 10.1016/j.ijbiomac.2015.09.031

Yuan, T. T., DiGeorge Foushee, A. M., Johnson, M. C., Jockheck-Clark, A. R., and Stahl, J. M. (2018). Development of electrospun chitosan-polyethylene oxide/fibrinogen biocomposite for potential wound healing applications. Nanoscale Res. Lett. 13:88. doi: 10.1186/s11671-018-2491-8

Zamani, M., Prabhakaran, M. P., and Ramakrishna, S. (2013). Advances in drug delivery via electrospun and electrosprayed nanomaterials. Int. J. Nanomedicine 8, 2997-3017. doi: 10.2147/IJN.S43575

Zhang, N., Deng, Y., Tai, Q., Cheng, B., Zhao, L., Shen, Q., et al. (2012). Electrospun $\mathrm{TiO}_{2}$ nanofiber-based cell capture assay for detecting circulating tumor cells from colorectal and gastric cancer patients. Adv. Mater. 24, 2756-2760. doi: 10.1002/adma.201200155

Zhao, G., Bao, X., Huang, G., Xu, F., and Zhang, X. (2019). Differential effects of directional cyclic stretching on the functionalities of engineered cardiac tissues. ACS Appl. Biol. Mater. 2, 3508-3519. doi: 10.1021/acsabm.9b00414

Ziade, M., Domergue, S., Batifol, D., Jreige, R., Sebbane, M., Goudot, P., et al. (2013). Use of botulinum toxin type A to improve treatment of facial wounds: a prospective randomised study. J. Plast. Reconstr. Aesthet. Surg. 66, 209-214. doi: 10.1016/j.bjps.2012.09.012

Ziyadeh, N., Fife, D., Walker, A. M., Wilkinson, G. S., and Seeger, J. D. (2011). A matched cohort study of the risk of cancer in users of becaplermin. Adv. Skin Wound Care 24, 31-39. doi: 10.1097/01.ASW.0000392922. 30229.b3

Conflict of Interest: The author declares that the research was conducted in the absence of any commercial or financial relationships that could be construed as a potential conflict of interest.

Copyright (c) 2020 Mulholland. This is an open-access article distributed under the terms of the Creative Commons Attribution License (CC BY). The use, distribution or reproduction in other forums is permitted, provided the original author(s) and the copyright owner(s) are credited and that the original publication in this journal is cited, in accordance with accepted academic practice. No use, distribution or reproduction is permitted which does not comply with these terms. 